Atmos. Chem. Phys., 18, 12413-12431, 2018

https://doi.org/10.5194/acp-18-12413-2018

(c) Author(s) 2018. This work is distributed under

the Creative Commons Attribution 4.0 License.

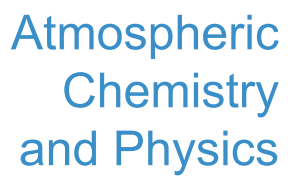

(c) (P)

\title{
Evidence for pyrazine-based chromophores in cloud water mimics containing methylglyoxal and ammonium sulfate
}

\author{
Lelia Nahid Hawkins ${ }^{1}$, Hannah G. Welsh ${ }^{1}$, and Matthew V. Alexander ${ }^{2}$ \\ ${ }^{1}$ Department of Chemistry, Harvey Mudd College, 301 Platt Blvd, Claremont, CA 91711, USA \\ ${ }^{2}$ Department of Chemistry, Pomona College, Claremont, CA 91711, USA
}

Correspondence: Lelia Nahid Hawkins (lhawkins@g.hmc.edu)

Received: 22 January 2018 - Discussion started: 7 February 2018

Revised: 10 June 2018 - Accepted: 5 August 2018 - Published: 28 August 2018

\begin{abstract}
Simulating aqueous brown carbon (aqBrC) formation from small molecule amines and aldehydes in cloud water mimics provides insight into potential humic-like substance (HULIS) contributors and their effect on local and global aerosol radiative forcing. Previous work has shown that these (Maillard type) reactions generate products that are chemically, physically, and optically similar to atmospheric HULIS in many significant ways, including in their complexity. Despite numerous characterization studies, attribution of the intense brown color of many aqBrC systems to specific compounds remains incomplete. In this work, we present evidence of novel pyrazine-based chromophores (PBCs) in the product mixture of aqueous solutions containing methylglyoxal and ammonium sulfate. PBCs observed here include 2,5-dimethyl pyrazine (DMP) and products of methylglyoxal addition to the pyrazine ring. This finding is significant as the literature of Maillard reactions in food chemistry tightly links the formation of pyrazine (and related compounds) to browning in foods. We investigated the roles of both cloud processing (by bulk evaporation) and $\mathrm{pH}$ in absorptivity and product distribution in microliter samples to understand the contribution of these $\mathrm{PBCs}$ to aqBrC properties. In agreement with previous work, we observed elevated absorptivity across the entire UV-visible spectrum following simulated cloud processing as well as higher absorptivity in more basic samples. Absorptivity of the $\mathrm{pH} 2$ sample, following evaporation over a period of days, exceeded that of the unevaporated $\mathrm{pH} 9$ sample. In addition, mixtures of ammonium sulfate and methylglyoxal at $\mathrm{pH} 5$ that were dried in under $1 \mathrm{~h}$ and analyzed $24 \mathrm{~h}$ later were as absorptive as $\mathrm{pH} 9$ samples allowed to react for 7 days, indicating that evaporation occurring during cloud processing may provide a reaction path-
\end{abstract}

way favorable for carbonyl-ammonia chemistry even under acidic conditions of aerosol and cloud water. The fraction of pyrazine compounds in the product mixture increased by up to a factor of 4 in response to drying with a maximum observed contribution of $16 \%$ at $\mathrm{pH} 5$. Therefore, cloud processing under acidic conditions may produce PBCs at the expense of imine- and imidazole-derived compounds. This finding has implications for further $\mathrm{BrC}$ reactivity and degradation pathways.

\section{Introduction}

Light-absorbing organic carbon in atmospheric aerosol (brown carbon or $\mathrm{BrC}$ ) has been shown to impact radiative forcing with an estimated contribution of $19 \%$ to total aerosol absorption globally (Feng et al., 2013). AERONET measurements over California have shown that in the brown carbon region $(440 \mathrm{~nm})$, brown carbon absorption is $40 \%$ of that attributed to elemental carbon (Bahadur et al., 2012). Further, attribution of brown carbon absorption to elemental carbon can lead to overestimates in the predicted direct radiative forcing of elemental carbon, creating large modelmeasurement differences in aerosol forcing and increasing the uncertainty in global climate models (Wang et al., 2014). Therefore, an accurate representation of aerosol-climate interactions in models is not possible without correctly accounting for this ubiquitous material. Its formation and persistence are dependent on $\mathrm{BrC}$ precursors, making it highly variable and difficult to constrain. $\mathrm{BrC}$ has both primary and secondary sources including biomass burning, fossil fuel combustion, and non-combustion biogenic emissions 
(Laskin et al., 2015). Among the secondary sources are both gas-phase and aqueous-phase reactions. For example, nitrated aromatics formed in gas-phase reactions between aromatics and nitrogen oxides are a significant source of $\mathrm{BrC}$ in urban environments like Los Angeles (Zhang et al., 2011). Aqueous-phase reactions, in contrast, appear to form larger and highly functionalized chromophores that often include reduced nitrogen species (Baduel et al., 2010; Duarte et al., 2004). This material can be formed in Maillard-type reactions between small carbonyl compounds and ammonia or amines, which have been shown to produce oligomeric species and $\mathrm{BrC}$ chromophores (termed aqueous brown carbon or aqBrC); a few representative studies include De Haan et al. (2011), Kampf et al. (2012), Nguyen et al. (2012), Lee et al. (2013), Laskin et al. (2014), and Lin et al. (2015). Even simple aqueous mixtures of one dicarbonyl (glyoxal or methylglyoxal, MG) and ammonia or a small amine produce myriad products and, under most conditions, yellow to brown color. In fact, $\mathrm{BrC}$ that is generated this way often resembles atmospheric humic-like substance (HULIS) across a number of metrics, such as the UV-visible absorption profile, mass spectral characteristics, and hygroscopicity (Hawkins et al., 2016). Given that global secondary organic aerosol (SOA) production from glyoxal and MG alone accounts for an estimated 2.6 and $8 \mathrm{Tg} \mathrm{Cyr}^{-1}$, respectively (Fu et al., 2008), and that $90 \%$ of their irreversible uptake occurs in clouds, Maillard-type reactions producing aqBrC could be an important global source of $\mathrm{BrC}$.

Although careful work has suggested that organonitrogen species are largely responsible for the bulk absorptivity of these amine-aldehyde systems (Bones et al., 2010), only a handful of aqBrC chromophores have been positively identified (Kampf et al., 2012; Nguyen et al., 2012; Laskin et al., 2014; Lin et al., 2015; Aiona et al., 2017a). Most of these are functionalized and conjugated imidazole products, summarized in detail in a recent review (Laskin et al., 2015). In many cases, the products incorporate two or three nitrogen atoms through nucleophilic attack on a carbonyl by an amine or ammonia; the products often grow through aldol condensation of MG or glyoxal, which may be acid (or base) catalyzed. The mechanistic details of aqBrC formation, including the roles of $\mathrm{pH}$ and evaporation and the persistence of product chromophores, are still incomplete, yet some trends in aqBrC absorptivity have been identified. In most cases, it was observed that chromophores form fastest in basic solution. This is consistent with the proposed mechanism involving nitrogen (in ammonia, methylamine, or amino acids) initiating a nucleophilic attack at the carbonyl carbon atom (Yu et al., 2011; Kampf et al., 2012). However, several studies have shown that aldol condensation of dicarbonyls can be acid catalyzed (Noziere et al., 2009) and that aldol condensation products may contribute to visible light absorption (Sareen et al., 2010). This leaves the relationship between $\mathrm{pH}$ and absorptivity in amine-aldehyde reactions unclear. For example, Sareen et al. (2010) showed that the peak absorbance (located at $282 \mathrm{~nm}$ ) in the products of MG/ammonium sulfate (AS) was linearly inversely related to the $\mathrm{pH}$ of samples after $24 \mathrm{~h}$ and concluded that the formation of light-absorbing products is enhanced by the presence of ammonium and hydronium ions through the acidcatalyzed aldol condensation mechanism. In a related study, Kampf et al. (2012) observed a novel, highly absorptive chromophore in the glyoxal-AS system, the imidazole bicycle, whose production rate declined as the $\mathrm{pH}$ of the reaction dropped. Similarly, Yu et al. (2011) observed an exponential dependence on $\mathrm{pH}$ for the rate of formation of imidazole and related products and concluded that available ammonia, dictated by solution $\mathrm{pH}$, drives this relationship. In the context of food chemistry, it is thought that neutral or slightly alkaline conditions favor melanoidins generally (Kwak et al., 2005) and in particular dimethylpyrazine (Koehler and Odell, 1970). Generally, it appears that basic conditions favor chromophore formation for these reactions, limiting their potential for brown carbon formation in (slightly acidic) atmospheric water. Further, a number of these systems have been shown to generate acidic side products, such that even under favorable initial conditions, the potential for brown carbon formation appears negligible (Kampf et al., 2012). There may exist $\mathrm{pH}$-dependent branching ratios in these reactions, favoring one type of chromophore over another. Noziere et al. (2009) observed that the iminium ion pathway, incorporating $\mathrm{N}$, is faster at a higher $\mathrm{pH}$ while the traditional aldol condensation is favored at a lower $\mathrm{pH}$. This suggests that the incorporation of $\mathrm{N}$-containing products has a $\mathrm{pH}$ dependence as well.

Previous studies have also established a correlation between aqBrC absorptivity and cloud processing (Nguyen et al., 2012; Lee et al., 2013; Powelson et al., 2013; Aiona et al., 2017b). Here cloud processing refers to the cycle of deliquescence to form cloud droplets, aqueous-phase reactions, evaporation of those droplets to form residual particles, subsequent deliquescence, and so forth. Cloud processing was simulated in this and related work by dissolving reactants or aqueous extracts of SOA in water and then allowing the solution to evaporate either in droplets (Lee et al., 2013) or in bulk solutions. The absorptivity of the evaporated and redissolved solution in such simulations is significantly higher than the absorptivity of the mixed reagents that never undergo evaporation. Many of the proposed mechanisms for chromophore formation involve condensation (elimination of water), which is consistent with the observed browning. This seems to suggest that cloud processing increases $\mathrm{BrC}$ absorptivity irreversibly on the timescales studied. Evaporation during cloud processing also serves to increase reactant concentrations and decrease $\mathrm{pH}$, though the interplay of these effects is not understood. In particular, it has been shown that for laboratory-generated limonene SOA, browning by evaporation is $\mathrm{pH}$ dependent (Nguyen et al., 2012). Under acidification to $\mathrm{pH} 2$ with sulfuric acid, browning by organosulfate formation can occur during evaporation. Under mildly 
acidic conditions, the chromophores are thought to be imidazole based. The absorption spectrum of the evaporated SOA material contains a stronger peak at $500 \mathrm{~nm}$ but lacks the shoulders at 430 and $570 \mathrm{~nm}$ observed under aqueous aging conditions. This suggests that evaporation serves mostly to increase the rate of formation of the predominant chromophores (around $500 \mathrm{~nm}$ ) but that some chemical differences exist between products of aqueous aging and products of repeated deliquescence and evaporation resulting from cloud processing. The authors suggest that evaporation may produce a narrower range of compounds than slower aqueous aging. In droplet evaporation experiments, Lee et al. (2013) show that evaporation of $10-50 \mathrm{mM}$ solutions of glyoxal and AS can generate more absorptive material than aqueous aging experiments.

In this study we use chemical ionization mass spectrometry in concert with isotopically labeled AS to elucidate the roles of $\mathrm{pH}$ and evaporation in forming brown carbon chromophores from MG and AS. Specifically, we evaluate whether the increased absorptivity generated by evaporation is greater than the $\mathrm{pH}$ effect observed in previous studies. Strong evidence is presented indicating that novel pyrazinebased chromophores form in this model system and that their contribution to total absorbance may be greatest under atmospherically relevant conditions.

\section{Methods}

\subsection{Reagents and sample preparation}

We prepared $1 \mathrm{M}$ stock solutions of each of the following reagents using low total organic carbon (TOC), $18 \mathrm{M} \Omega$ resistivity water without further purification $(40 \mathrm{wt} \%$ methylamine solution in water; Sigma Aldrich), $40 \mathrm{wt} \%$ MG solution in water (SAFC), glyoxal trimer dihydrate (Fluka Analytical), and AS (Sigma Aldrich). A $1 \mathrm{M}$ solution of isotopically labeled AS $\left({ }^{15} \mathrm{NH}_{4}\right)_{2} \mathrm{SO}_{4}$ (Sigma Aldrich) was used to investigate the number of $\mathrm{N}$ atoms incorporated into products. The $18 \mathrm{M} \Omega$ resistivity water was verified as having less than $5 \mathrm{ppb}$ of TOC by TOC analysis.

Each sample was prepared in a manner similar to De Haan et al. (2011) by combining $75 \mu \mathrm{L}$ of $1 \mathrm{M} \mathrm{AS}$ or ${ }^{15} \mathrm{~N}$ AS with $75 \mu \mathrm{L}$ of $1 \mathrm{M}$ MG in a $7.4 \mathrm{~mL}$ glass vial. An additional $45 \mathrm{uL}$ of water, $1 \mathrm{M} \mathrm{NaOH}$, or a combination was used to set the initial reaction $\mathrm{pH}$ at either $2,5,7$, or 9 . Vials were left to react in a dark hood. Control samples were prepared without AS. In addition, samples were analyzed after $10 \mathrm{~min}$ of reaction time. After 7 days, uncapped vials contained brown dried residual material and capped vials contain colored solutions. For fast-drying experiments, $\mathrm{pH} 5$ samples were prepared and dried with ultra-high-purity nitrogen over the course of $1 \mathrm{~h}$ and analyzed immediately and again $24 \mathrm{~h}$ later. This process was repeated using HEPA-filtered laboratory air instead of nitrogen. In order to evaluate if the products form un- der cloud droplet evaporation timescales, particles were collected by atomizing a solution of $50 \mathrm{mM}$ MG and $50 \mathrm{mM}$ AS, adjusted to $\mathrm{pH}$ 5. The atomized aerosol was collected directly onto the glass capillary used for atmospheric pressure chemical ionization (APCI) and was analyzed after $30 \mathrm{~min}$ of sample collection.

\subsection{Absorptivity}

The solution mass absorption coefficient $\mathrm{MAC}_{\mathrm{soln}}$ as a function of wavelength was determined by UV-visible absorbance and TOC measurements following Hecobian et al. (2010) and Zhang et al. (2011, 2013). The spectroscopic setup includes a World Precision Instruments 3000 Series Liquid Waveguide Capillary Cell (LWCC-3100) with a $94 \mathrm{~cm}$ optical path length and an internal volume of $250 \mu \mathrm{L}$, an Ocean Optics lamp (DT-Mini-2), and an Ocean Optics detector (USB4000-UV-Vis). A Sievers $5310 \mathrm{C}$ laboratory TOC analyzer was used to obtain TOC concentrations using $15 \%$ ammonium persulfate $\left(0.4 \mu \mathrm{L} \mathrm{min}{ }^{-1}\right.$ flow rate $)$ as the oxidizer and $6 \mathrm{M}$ phosphoric acid $\left(1.0 \mu \mathrm{L} \mathrm{min}^{-1}\right.$ flow rate). The reacted samples were diluted with $100 \mathrm{~mL}-1 \mathrm{~L}$ of water, depending on the intensity of light absorbance of the sample, in order to remain within the linear range of the Beer-Lambert relationship (measured absorbance less than 1 beyond $300 \mathrm{~nm}$ ). Solutions were drawn through the waveguide and into the TOC at a rate of $0.5 \mathrm{~mL} \mathrm{~min}^{-1}$ set by the TOC online sampling rate. Over the course of $30 \mathrm{~min}, 10 \mathrm{ab}$ sorbance spectra and at least three TOC readings were collected for each discrete sample. These values were averaged to obtain MAC bulk spectra shown in Fig. 1. Water blanks were used between samples to avoid contamination and ensure readings return to nominally blank conditions.

Absorptivity in units of $\mathrm{m}^{2} \mathrm{~g} \mathrm{OC}^{-1}$ is determined for each wavelength according to the following equation:

$\mathrm{MAC}_{\text {soln }}=\frac{A_{\lambda}-A_{\text {ref }}}{(0.94 \mathrm{~m})\left(\mathrm{TOC}_{\mathrm{ppm}}\right)} \ln (10)$,

where $A_{\text {ref }}$ is the absorbance in the reference region of 650 $710 \mathrm{~nm}$ where no $\mathrm{BrC}$ absorbance is observed and is used to correct for changes in the total light transmittance due to movement of the fiber optic cables (Hecobian et al., 2010; Zhang et al., 2011, 2013).

\subsection{Atmospheric pressure chemical ionization mass spectrometry}

An Advion compact mass spectrometer (CMS) with ASAP probe injection and APCI was used to obtain intact molecular ions (typically $\mathrm{M}+\mathrm{H}^{+}$) for both ${ }^{14} \mathrm{~N}$ - and ${ }^{15} \mathrm{~N}$-containing samples. With the ASAP probe, both liquids and solids can be analyzed directly without extraction or even dissolution. The probe tip is dipped into the liquid sample or touched to the solid residue and inserted directly into the mass spectrometer. Conditions of ionization were nominally low temperature and low fragmentation, meaning the capillary tube 

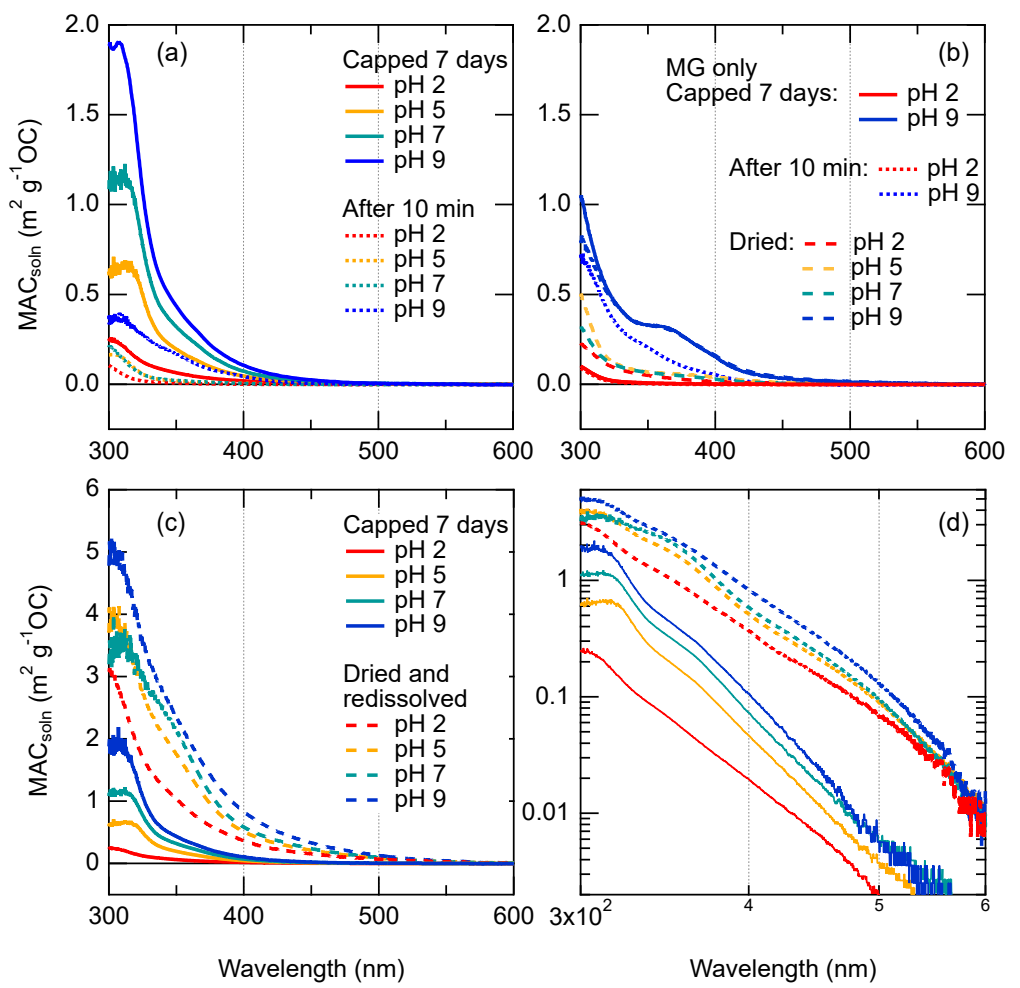

Figure 1. Normalized UV-visible absorbance spectra (displayed as mass absorption coefficient) for (a) methylglyoxal (1.0 M) and ammonium sulfate $(1.0 \mathrm{M})$ reactions after $10 \mathrm{~min}$ and after 7 days of reaction time, (b) control experiments without ammonium sulfate, (c) solutions in (a) after evaporation to dryness and (d) log-log plot of all spectra in (c). Spectra have been baseline corrected using the measured absorbance between 650 and $710 \mathrm{~nm}$.

was at $135^{\circ} \mathrm{C}$, the source gas was $250^{\circ} \mathrm{C}$, and the capillary voltage was $120 \mathrm{~V}$ (source voltage held at $20 \mathrm{~V}$ ). The corona discharge was held at $5 \mu \mathrm{A}$. A quadrupole mass spectrometer provides unit mass resolution spectra as the compounds are volatilized from the probe tip.

\section{Results and discussion}

\subsection{General absorbance and mass spectral characteristics}

Figure 1a shows the measured absorptivity for the products of MG-AS under all four $\mathrm{pH}$ starting conditions studied including $\mathrm{pH} 2,5,7$, and 9 in capped samples after $10 \mathrm{~min}$ of reaction time and 7 days later. Spectra from experimental control samples prepared without AS are shown in Fig. 1b. Figure 1c shows the measured absorptivity for the same reaction in both dried and capped samples. The log-log plot (representing the absorption Ångström exponent, AAE) for each sample is shown in Fig. 1d. All spectra are characterized by an absorption maximum at or near $300 \mathrm{~nm}$ with tails of varying intensity into the visible region. The acidic and neutral samples in Fig. 1a have negligible absorbance. The pH 9 sample was more absorptive after $10 \mathrm{~min}$ than the $\mathrm{pH} 2$ sam- ple after 7 days, supporting the idea that brown carbon formation is favored in basic solutions. Figure $1 \mathrm{~b}$ shows the absorptivity of solutions containing only MG under three treatments (dried, capped for 7 days, or analyzed $10 \mathrm{~min}$ after preparation). Dried samples of MG at pH 2-7 did produce small but measurable absorbance between 350 and $400 \mathrm{~nm}$. The dried and capped $\mathrm{pH} 9$ control samples were more absorptive than the capped $\mathrm{pH} 9$ mixture but significantly less absorptive than the same reaction following evaporation. The control experiments indicate that although MG can form light-absorbing compounds in self-reactions under basic conditions, the potential for brown carbon to form from self-reactions under neutral or acidic conditions is limited.

Samples that reacted without evaporation (capped) share a steep decline in absorptivity after $325 \mathrm{~nm}$ and measurable absorbance up to about $425 \mathrm{~nm}$; beyond $450 \mathrm{~nm}$, no absorbance was observed. In contrast, the dried and redissolved samples possess measurable absorbance beyond $500 \mathrm{~nm}$ with clear shoulders at $350 \mathrm{~nm}$. As summarized in Table 1, $\mathrm{MAC}_{365}$ for the capped and dried samples ranges from 0.05 to $0.22 \mathrm{~m}^{2} \mathrm{~g}^{-1} \mathrm{OC}$ (capped) and from 0.59 to $1.13 \mathrm{~m}^{2} \mathrm{~g}^{-1} \mathrm{OC}$ (dried). These values compare well to watersoluble OC from ambient measurements in the Bay of Bengal $\left(0.2-1.5 \mathrm{~m}^{2} \mathrm{~g}^{-1}\right.$ at $365 \mathrm{~nm}$ by Srinivas and Sarin, 2013) in 

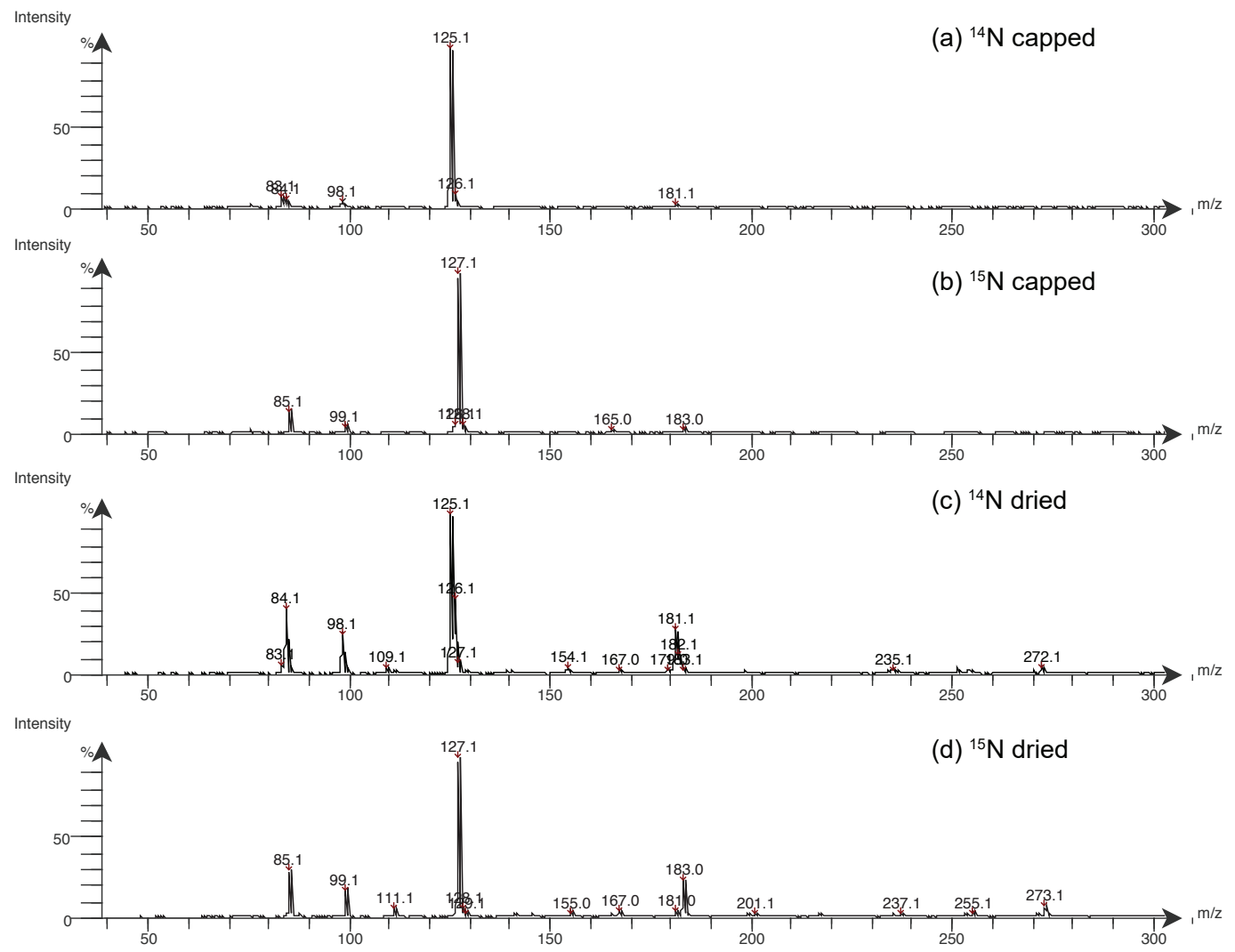

Figure 2. Atmospheric pressure chemical ionization (APCI) mass spectra for all four reactions (after 7 days) between $1.0 \mathrm{M}$ methylglyoxal and $1.0 \mathrm{M}$ ammonium sulfate $(\mathrm{pH} 2$ ) including those with and without isotopically labeled $\mathrm{N}$. Intensity is set to $100 \%$ for the largest signal and does not correspond to concentration in the sample itself.

Delhi $\left(2.7 \mathrm{~m}^{2} \mathrm{~g}^{-1}\right.$ at $300 \mathrm{~nm}$ by Kirillova et al., 2013) and in Chinese outflow observed in Gosan, Korea $\left(0.8-1.1 \mathrm{~m}^{2} \mathrm{~g}^{-1}\right.$ at $365 \mathrm{~nm}$ by Kirillova et al., 2014). Previous laboratory simulations of $\mathrm{aqBrC}$ formation report lower values of $\mathrm{MAC}_{365}$ in the range of $100-500 \mathrm{~cm}^{2} \mathrm{~g}^{-1}$ (Powelson et al., 2013) for these and similar mixtures. AAEs in this study cover smaller ranges and show less dependence on $\mathrm{pH}$ than $\mathrm{MAC}_{365}$, with AAE values from 9-12 for capped samples and from 7.7 to 8.9 for dried samples, which is well within the range observed in Srinivas and Sarin (2013), Kirillova et al. (2013), and Kirillova et al. (2014). The role of evaporation in altering absorptivity and generating products is discussed further in the following sections.

Samples containing ${ }^{14} \mathrm{~N}$ AS and ${ }^{15} \mathrm{~N}$-labeled AS were used pairwise for each reaction condition ( $\mathrm{pH}$ and evaporation) to determine the number of $\mathrm{N}$ atoms in each major product of the MG-AS system. As is seen by comparing Fig. 2a to b and Fig. 2c to d, nearly all of the masses observed by APCI incorporate at least one $\mathrm{N}$ atom and most incorporate two $\mathrm{N}$ atoms. One product $(m / z 162$, not visible at $\mathrm{pH} 2)$ incorporates three $\mathrm{N}$ atoms; $m / z, 165$ is barely visible in Fig. $2 \mathrm{~b}$. Only a few observed products, $m / z 167,199$, and 271, show
Table 1. Absorptivity (as mass absorption coefficient, MAC) and absorption Ångström exponent (AAE) for dried and capped samples for each initial $\mathrm{pH}$ condition.

\begin{tabular}{lrr}
\hline Sample & MAC $_{365}\left(\mathrm{~m}^{2} \mathrm{~g}^{-1}\right)$ & $\mathrm{AAE}$ \\
\hline Capped samples & & \\
pH 2 & 0.05 & 9 \\
pH 5 & 0.12 & 11 \\
pH 7 & 0.17 & 12 \\
pH 9 & 0.22 & 12 \\
\hline Dried samples & & \\
pH 2 & 0.59 & 7.7 \\
pH 5 & 0.75 & 8.6 \\
pH 7 & 0.78 & 8.9 \\
pH 9 & 1.13 & 8.0 \\
\hline
\end{tabular}

the same masses in both ${ }^{14} \mathrm{~N}$ and ${ }^{15} \mathrm{~N}$ samples. $m / z 167$ is consistent with a MG self-reaction product reported in $\mathrm{Sa}-$ reen et al. (2010) as $\mathrm{C}_{6} \mathrm{H}_{15} \mathrm{O}_{5}^{+}$and another $\mathrm{MG}$ self-reaction product in Lin et al. (2015) reported as $\mathrm{C}_{9} \mathrm{H}_{10} \mathrm{O}_{3}^{+}$. Without a high-resolution mass spectrum, we are unable to say which 


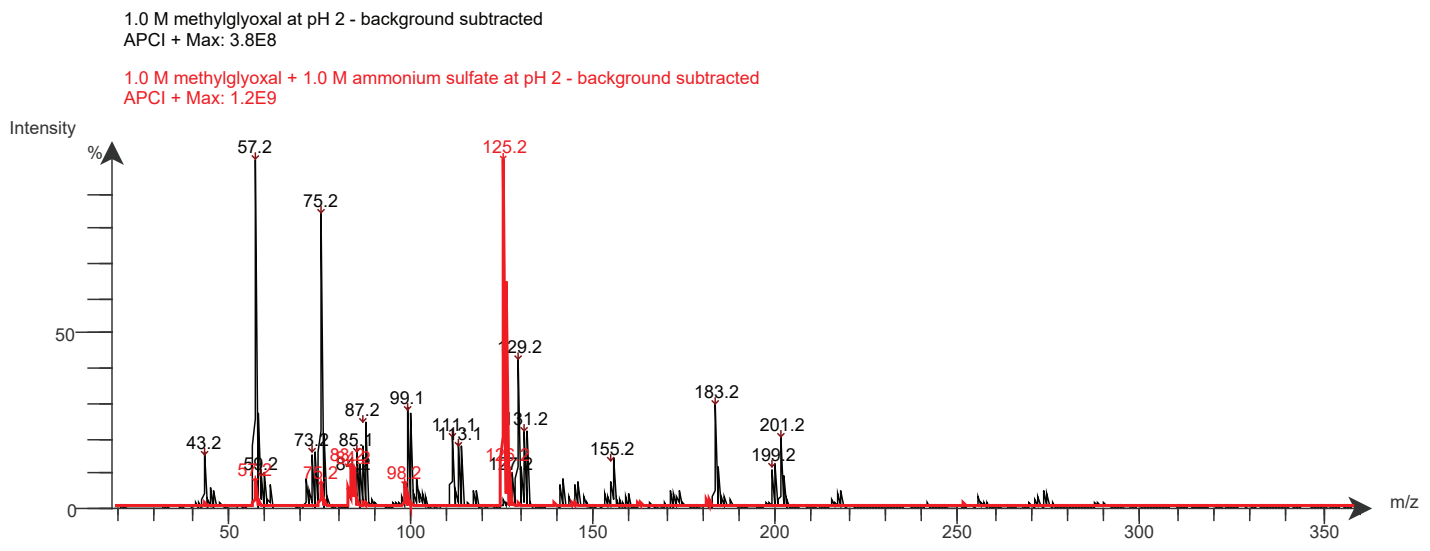

Figure 3. Atmospheric pressure chemical ionization (APCI) mass spectra for $1.0 \mathrm{M}$ methylglyoxal at $\mathrm{pH} 2$ (black) and the reaction with $1.0 \mathrm{M}$ ammonium sulfate after $10 \mathrm{~min}$ (red). Intensity is set to $100 \%$ for the largest signal and does not correspond to concentration in the sample itself.

product is more likely forming in this study. However, the C9 compound was reported based on high-resolution work in Lin et al. (2015) while the C6 product was based on $1 \mathrm{amu}$ resolution data; therefore the evidence for the $\mathrm{C} 9$ compound is stronger. $m / z 199$ and 271 are also identified as MG selfreaction products. $m / z 199$ was assigned the molecular formula $\mathrm{C}_{10} \mathrm{H}_{14} \mathrm{O}_{4}$ in Lin et al. (2015) though its structure remains undetermined; $m / z 271$ is very likely one MG addition to $m / z$ 199. The masses observed in the $\mathrm{pH} 2$ samples in Fig. 2 compose most but not all of the products observed across all samples though the ratio of products is $\mathrm{pH}$ dependent. APCI spectra for the remaining initial $\mathrm{pH}$ conditions ( $\mathrm{pH} 5,7$, and 9) under both capped and dried conditions are provided in the Supplement as Figs. S1-S3.

Figure 3 shows a direct comparison of the MG control at $\mathrm{pH} 2$ and the reaction with AS after only $10 \mathrm{~min}$. In Fig. 3 and other control spectra for MG, $m / z 75$ appears much larger than the $(\mathrm{M}+\mathrm{H})^{+}$ion for $\mathrm{MG}, m / z 73$. This is likely hydroxyacetone, a disproportionation product of MG that corresponds to $(\mathrm{M}+3 \mathrm{H})^{+} . m / z 43$ results from the loss of $\mathrm{CHO}$ from $m / z 73$ while $m / z 57$ corresponds to $\left(\mathrm{M}+3 \mathrm{H}-\mathrm{H}_{2} \mathrm{O}\right)^{+}$. We hypothesize that the conditions of ionization determine whether $m / z 73$ or $m / z 75$ forms preferentially. For example, Zhou et al. (2018) observed $m / z 75$ by APCI in the product spectrum of the reaction between MG and hydrogen peroxide. After only $10 \mathrm{~min}$, peaks attributed to $\mathrm{MG}$ are considerably smaller while $m / z 125$ (methylimidazole) becomes the most abundant ion. Figures S4-S7 show the initial APCI spectra for the $\mathrm{pH} 2-9$ reactions between MG and AS in which the same behavior is observed. Figures S8 and S9 show APCI spectra for control experiments using only MG under both capped and dried conditions. A number of products identified in self-reactions of drying MG by highresolution aerosol mass spectrometry (HR-AMS) in De Haan et al. (2009b) are visible in the control spectra including $m / z 111,129,201$. None of the N-containing products described in the samples were visible in the control spectra.

Many of the N-containing masses detected through APCI mass spectrometry (APCI-MS) have been observed previously in MG-AS reactions with electrospray ionization (De Haan et al., 2011; Lin et al., 2015; Aiona et al., 2017a) or aerosol chemical ionization with $\mathrm{H}_{3} \mathrm{O}^{+}$and $\mathrm{I}^{-}$(Sareen et al., 2010) and their structures have been proposed with various levels of confidence in those studies. Table 2 provides masses and tentative structures for $\mathrm{N}$-containing products observed here that are either identical to or consistent with those observed previously. These products can be grouped into one of two categories: imidazole-based compounds $(m / z 83,97$, $125,197,232$, and 251) and linear imine-containing compounds $(m / z 144,180,216$, and 288). Our observations support the structural assignments in those studies; for example, we observed $m / z 180$ more often in dried samples and $\mathrm{m} / z 216$ (completely hydrated form of $m / z$ 180) only in $\mathrm{pH} 7$ and 9 capped samples.

\subsection{Pyrazine-based chromophores}

In addition to imidazole-based and imine-containing products in Table 2, a series of products separated by $72 \mathrm{amu}$, beginning with $m / z 109$ and all containing two $\mathrm{N}$ atoms, was observed in nearly all samples. $m / z, 109$ was reported as a MG-AS reaction product by electrospray ionization in Lin et al. (2015), without structural assignment but with a molecular formula of $\mathrm{C}_{6} \mathrm{H}_{9} \mathrm{~N}_{2}^{+}$based on the exact mass. In addition, two products related to the delta- 72 series by loss of $18 \mathrm{amu}$ and still containing two $\mathrm{N}$ atoms were also observed with high frequency. Given the exact chemical formula of $m / z 109$ in Lin et al. (2015) and the evidence outlined below, we propose that $m / z 109$ is 2,5-dimethylpyrazine and that masses separated by $72 \mathrm{amu}$ from $\mathrm{m} / z 109$ are methylglyoxal addition products to 2,5-dimethylpyrazine (2,5-DMP) 
Table 2. Proposed structures for products detected by APCI-MS that are either (a) previously reported or (b) analogs of previously reported compounds. In the case of type (a) compounds, citations are provided. The observed $m / z$ in ${ }^{15} \mathrm{~N}$ samples are provided in parentheses.

\begin{tabular}{|c|c|c|c|}
\hline$m / z\left(\right.$ in $\left.{ }^{15} \mathrm{~N}\right)$ & $\begin{array}{l}\text { Molecular } \\
\text { formula } \\
\text { of ion }\end{array}$ & Proposed structure of ion(s) & $\begin{array}{l}\text { Previous observations and prevalence } \\
\text { in this study }\end{array}$ \\
\hline $83(85)$ & $\mathrm{C}_{4} \mathrm{H}_{7} \mathrm{~N}_{2}^{+}$ & & $\begin{array}{l}\text { aDe Haan et al. (2011); second largest signal } \\
\text { in most samples, highest in pH } 9 .\end{array}$ \\
\hline 97 (99) & $\mathrm{C}_{5} \mathrm{H}_{9} \mathrm{~N}_{2}^{+}$ & & $\begin{array}{l}\text { a De Haan et al. (2011); only observed } \\
\text { above pH } 7 .\end{array}$ \\
\hline $125(127)$ & $\mathrm{C}_{6} \mathrm{H}_{9} \mathrm{~N}_{2} \mathrm{O}^{+}$ & & $\begin{array}{l}\text { a De Haan et al. (2011); Lin et al. (2015); } \\
\text { largest signal in all samples except pH } 9 .\end{array}$ \\
\hline $144(145)$ & $\mathrm{C}_{6} \mathrm{H}_{10} \mathrm{NO}_{3}^{+}$ & & $\begin{array}{l}\text { aLin et al. (2015); minor to very minor, } \\
\text { stronger signal in capped vials. }\end{array}$ \\
\hline $180(181)$ & $\mathrm{C}_{9} \mathrm{H}_{10} \mathrm{NO}_{3}^{+}$ & & $\begin{array}{l}\text { b Double dehydration product of } m / z 216 \text {; } \\
\text { very minor, observed in dried samples. }\end{array}$ \\
\hline 197 (199) & $\mathrm{C}_{9} \mathrm{H}_{13} \mathrm{~N}_{2} \mathrm{O}_{3}^{+}$ & & $\begin{array}{l}\text { a Lin et al. (2015); minor, stronger signal in } \\
\text { capped vials. }\end{array}$ \\
\hline $216(217)$ & $\mathrm{C}_{9} \mathrm{H}_{14} \mathrm{NO}_{5}^{+}$ & & $\begin{array}{l}{ }^{\mathrm{b}} \mathrm{MG} \text { addition product of } m / z 144 \text {; very minor, } \\
\text { only observed in capped } \mathrm{pH} 7-9 \text { samples. }\end{array}$ \\
\hline $232(235)$ & $\mathrm{C}_{12} \mathrm{H}_{14} \mathrm{~N}_{3} \mathrm{O}_{2}^{+}$ & & $\begin{array}{l}\text { aLin et al. (2015); Aiona et al. (2017a); } \\
\text { very minor, found in dried samples. }\end{array}$ \\
\hline $234(235)$ & $\mathrm{C}_{12} \mathrm{H}_{12} \mathrm{NO}_{4}^{+}$ & & 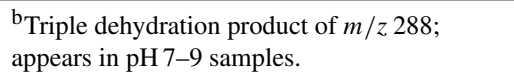 \\
\hline $251(253)$ & $\mathrm{C}_{12} \mathrm{H}_{15} \mathrm{~N}_{2} \mathrm{O}_{4}^{+}$ & & $\begin{array}{l}\text { a Lin et al. (2015); consistently observed in } \\
\text { dried samples. }\end{array}$ \\
\hline 288 (289) & $\mathrm{C}_{12} \mathrm{H}_{18} \mathrm{NO}_{7}^{+}$ & & $\begin{array}{l}{ }^{\mathrm{b}} \text { Double MG addition product of } m / z 144 \text {; } \\
\text { minor, favored in capped samples. }\end{array}$ \\
\hline
\end{tabular}


Table 3. Proposed structures for novel pyrazine-based chromophores matching the molecular weight and number of $\mathrm{N}$ atoms observed in this study. The observed $m / z$ in ${ }^{15} \mathrm{~N}$ samples is provided in parentheses. In some cases, the ion (but not the structure) was reported in a previous study.

\begin{tabular}{|c|c|c|c|}
\hline$m / z\left(\right.$ in $\left.{ }^{15} \mathrm{~N}\right)$ & $\begin{array}{l}\text { Molecular } \\
\text { formula of ion }\end{array}$ & $\begin{array}{l}\text { Proposed structure } \\
\text { of ion(s) }\end{array}$ & $\begin{array}{l}\text { Previous observations and prevalence } \\
\text { in this study }\end{array}$ \\
\hline 109 (111) & $\mathrm{C}_{6} \mathrm{H}_{9} \mathrm{~N}_{2}^{+}$ & & $\begin{array}{l}\text { Peak } 9 \text { in Lin et al. (2015); minor but } \\
\text { consistently observed in dried, acidic samples. }\end{array}$ \\
\hline $162(165)$ & $\mathrm{C}_{9} \mathrm{H}_{1} 2 \mathrm{~N}_{3}^{+}$ & & $\begin{array}{l}\text { Peak } 18 \text { in Lin et al. (2015); minor but } \\
\text { consistently observed; fourth largest signal } \\
\text { in pH } 7 \text { dried sample. }\end{array}$ \\
\hline $181(183)$ & $\mathrm{C}_{9} \mathrm{H}_{13} \mathrm{~N}_{2} \mathrm{O}_{2}^{+}$ & & $\begin{array}{l}\text { Minor but consistently observed in most samples; } \\
10 \% \text { of total signal in dried } \mathrm{pH} 2 \text { sample. }\end{array}$ \\
\hline 235 (237) & $\mathrm{C}_{12} \mathrm{H}_{15} \mathrm{~N}_{2} \mathrm{O}_{3}^{+}$ & & $\begin{array}{l}\text { Peak } 1 \text { in Lin et al. (2015); minor but consistent, } \\
\text { significantly larger in dried samples. } \\
\text { Regioisomer not shown. }\end{array}$ \\
\hline $253(255)$ & $\mathrm{C}_{12} \mathrm{H}_{17} \mathrm{~N}_{2} \mathrm{O}_{4}^{+}$ & & $\begin{array}{l}\text { Peak } 14 \text { in Lin et al. (2015); minor, slightly } \\
\text { favored in capped samples. }\end{array}$ \\
\hline 289 (291) & $\mathrm{C}_{15} \mathrm{H}_{17} \mathrm{~N}_{2} \mathrm{O}_{4}^{+}$ & & $\begin{array}{l}\text { Very minor, observed in dried samples only. } \\
\text { Regioisomer not shown. }\end{array}$ \\
\hline
\end{tabular}

formed by aldol-type condensation reactions. The masses separated by $18 \mathrm{amu}$ are also proposed as pyrazine-based structures, derived from dehydration. $m / z 162$ is proposed as an imine-substituted dehydration product of $\mathrm{m} / \mathrm{z} 181$ formed as shown in Scheme 3. Aromaticity of the heterocycle and frequent conjugation to the ring in these pyrazine products results in strong UV and (arguably) visible light absorption of the observed products; therefore, we will refer to these compounds as "pyrazine-based chromophores" (PBCs) to distinguish them from the compounds listed in Table 2. Table 3 provides a complete list of proposed PBCs, none of which have been previously reported with structural assign- 


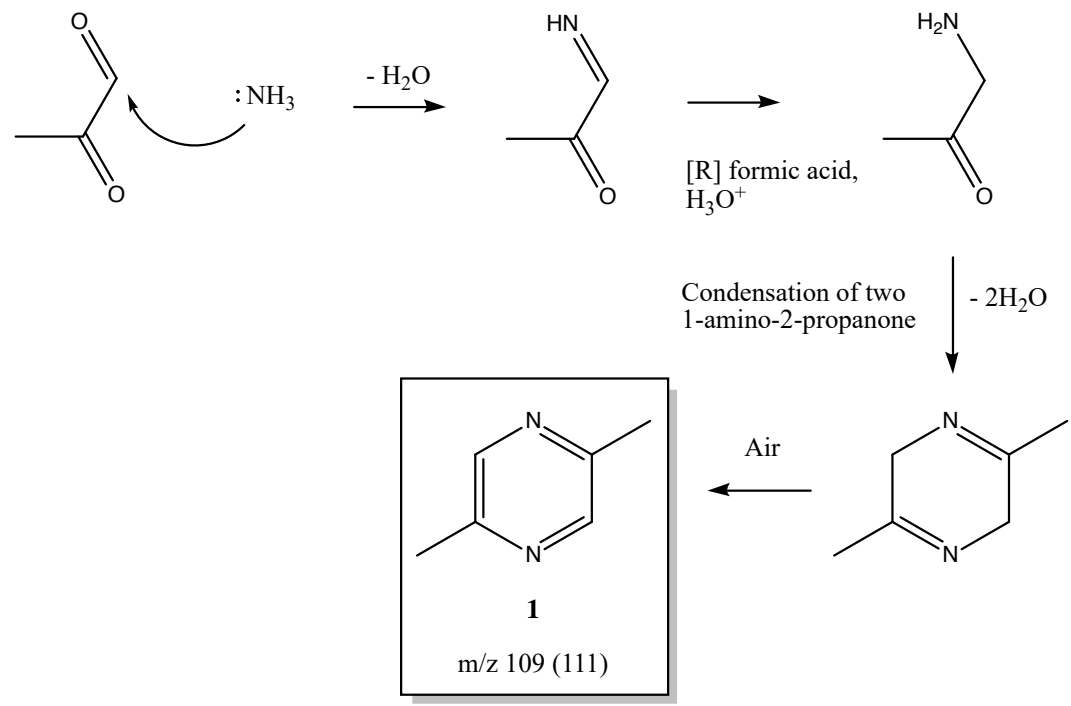

Scheme 1. Proposed formation mechanism of 2,5-dimethylpyrazine (1) from methylglyoxal and ammonium sulfate under mildly acidic conditions and in the presence of a reducing agent (formic acid) and atmospheric oxygen. This mechanism is slightly adapted from Fig. 4 of Divine et al. (2012), which begins with the accepted formation of 2,5-dimethylpyrazine described in Rizz (1972). A plausible alternative mechanism is the reduction of only one ketoimine and a subsequent hetero-isomerization, eliminating the need for the final oxidation step. The $(\mathrm{M}+\mathrm{H})^{+}$ion at $m / z 109$ and the $(\mathrm{M}+\mathrm{H})^{+}$ion formed with ${ }^{15} \mathrm{~N}$ at $m / z 111$ were observed by APCI. $m / z 108\left(\mathrm{M}^{+}\right)$was observed by GC-MS.

ments in atmospheric chemistry studies. A number of these structures have been reported, however, in the chemistry of Maillard reactions in food and food models (Adams et al., 2008; Van Lancker et al., 2010; Yu et al., 2017; Divine et al., 2012).

The strongest evidence supporting 2,5-DMP as the correct structural interpretation of $m / z 109$ is the result of gas chromatography-mass spectrometry (GC-MS) analyses of ethyl acetate extracts of dried samples (e.g., dried $\mathrm{pH} 2$; Fig. S10). The residual brown material was diluted to $0.5 \mathrm{~mL}$ with ultrapure water containing $130 \mathrm{ppm}$ pyrazine internal standard and adjusted to $\mathrm{pH} 9$ with $1.0 \mathrm{M} \mathrm{NaOH}$ to encourage solubility in ethyl acetate. In Fig. S10, the pyrazine internal standard is seen at $4.18 \mathrm{~min}$ of retention time (RT) and 2,5DMP is visible at $6.57 \mathrm{~min}$ RT. The fragmentation pattern for the spectrum at $6.57 \mathrm{~min}$ is a $81 \%$ match to the NIST library spectrum for 2,5-DMP, a $13 \%$ match to 2,6-DMP, and a less than $5 \%$ match to a series of other pyrazine-based compounds. Figure S11 shows the comparison of the "Quick Search" result for the same peak, indicating a $91 \%$ match between the instrument's default library and the observed spectrum at $6.57 \mathrm{~min}$. The same analysis was performed for dried samples at $\mathrm{pH} 5,7$, and 9. The peak area for 2,5-DMP in the gas chromatograms roughly corresponds to the $\mathrm{pH}$ dependence of PBCs measured by APCI described below, lending further support for this assignment.

There are three additional pieces of evidence pointing toward 2,5-DMP as the correct structure of $m / z$ 109. First, the authors in Lin et al. (2015) speculated that the uniden- tified product $\mathrm{C}_{6} \mathrm{H}_{8} \mathrm{~N}_{2}$ must be aromatic because of its larger affinity for the biphenyl column than the similar compound, $\mathrm{C}_{6} \mathrm{H}_{8} \mathrm{ON}_{2}$. Second, 2,5-DMP contains two intact MG groups and has a plausible formation mechanism from our starting materials under atmospherically relevant conditions (Scheme 1). This mechanism is described as "the most accepted formation mechanism for pyrazine" in Maillard reactions in food (Adams et al., 2008; Van Lancker et al., 2010) and is consistent with mechanisms presented in Van Lancker et al. (2010) (Scheme 1) and Yu et al. (2017). In addition, Divine et al. (2012) showed that among the four possible mechanisms of alkylpyrazine formation in aged Parmesan cheese, only the MG-based mechanism correctly explains the observed products. Third, 2,5-DMP in particular has been shown to form in focused studies of Maillard reactions in food, specifically in cases in which MG was exposed to amine-containing compounds (Adams et al., 2008; Van Lancker et al., 2010; Divine et al., 2012; Yu et al., 2017). In Van Lancker et al. (2010), the reaction of MG with heated free amino acids and lysine containing dipeptides produced 2,5(6)-DMP and trimethylpyrazine at 10-100 times the signal of other pyrazines. Its presence in relatively large quantities suggests that the energetics of the 2,5-DMP pathway are favorable. However, our reactions contain ammonia instead of amino acids as in the Maillard reactions between sugar (or dicarbonyls) and amino acids in food. Therefore, a reducing agent is necessary to explain the formation of 2,5-DMP from our starting materials. Formic acid, especially under acidic conditions, is a sufficiently strong reducing agent to com- 


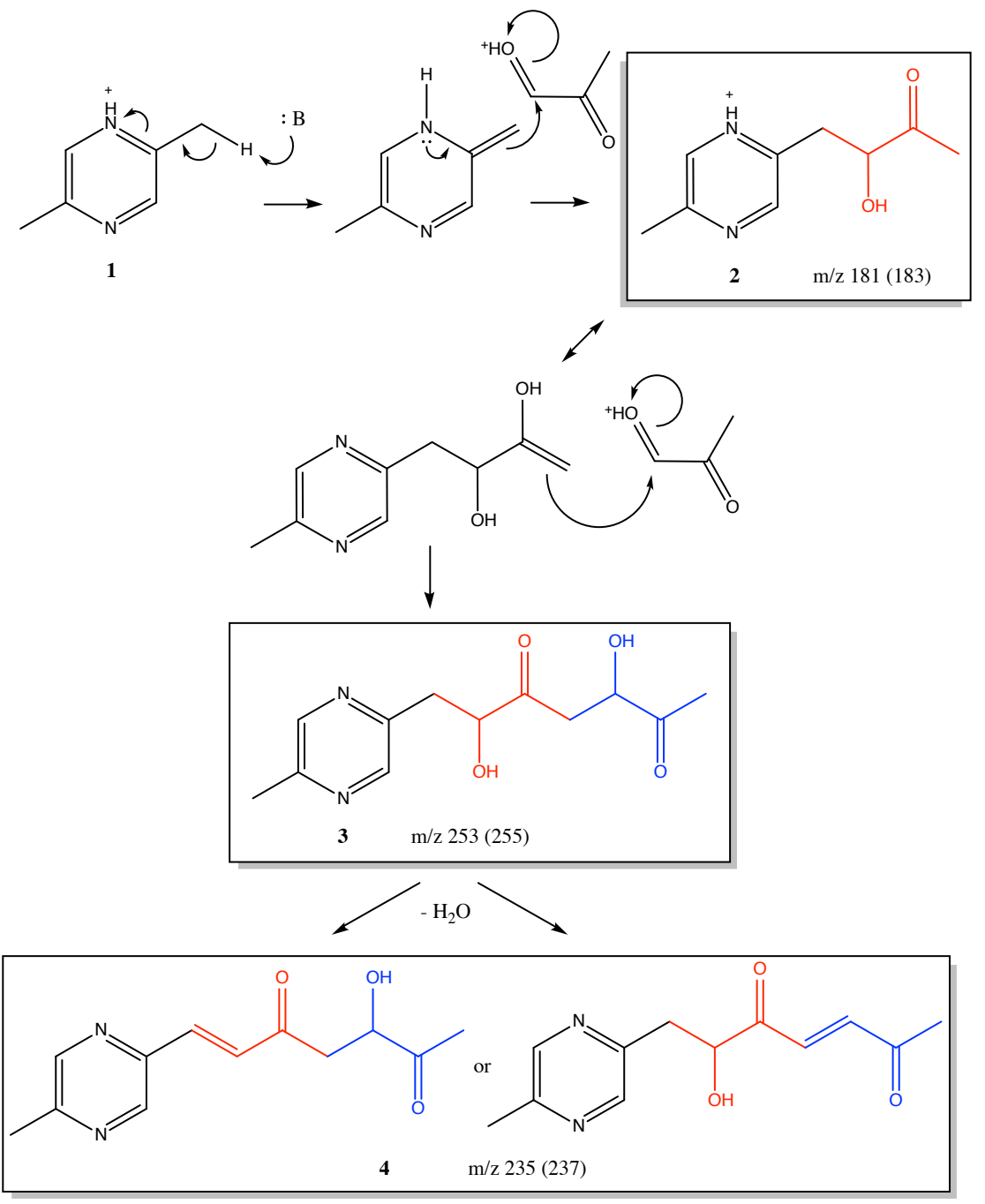

Scheme 2. Proposed formation mechanism of pyrazine-based chromophores (2), (3), and (4) with $m / z$ 181, 253, and 235 observed by APCI from 2,5-dimethylpyrazine and methylglyoxal. Masses expected and observed in samples prepared with ${ }^{15} \mathrm{~N}$ are given in parentheses. Addition of methylglyoxal here follows the mechanism presented in De Haan et al. (2011) for oligomerization of imidazole products in this same system. Red and blue are used to highlight individual and intact methylglyoxal units in the products that were directly observed by APCI-MS. Additional possible structures for $m / z, 253$ and 235 are shown in Table 3.

plete the reductive amination step as shown in Scheme 1 . Formic acid was not detected in this study in either positive or negative ion mode (as $m / z 47$ or 45 , respectively) but it has been reported as a side product of glyoxal-AS and MGAS in several other studies (Galloway et al., 2009; De Haan et al., 2009a; Sareen et al., 2010; Yu et al., 2011). The evidence outlined here lends confidence to our assignment of $\mathrm{m} / z 109$ as 2,5-DMP.

Observation of 2,5-DMP by GC-MS within our samples strengthens the structural assignment of related masses $(\mathrm{m} / \mathrm{z} 162,181,235,253$, and 289) in Table 3, but direct evidence of these compounds is still lacking. However, there are again several lines of evidence suggesting that MG adds to 2,5-DMP in an aldol-type reaction as proposed in Ta- ble 3 and Scheme 2 and not in another configuration. First, $m / z 162,235$, and 253 were reported in Lin et al. (2015) as $\mathrm{C}_{9} \mathrm{H}_{12} \mathrm{~N}_{3}^{+}, \mathrm{C}_{12} \mathrm{H}_{15} \mathrm{~N}_{2} \mathrm{O}_{3}^{+}$, and $\mathrm{C}_{12} \mathrm{H}_{17} \mathrm{~N}_{2} \mathrm{O}_{4}^{+}$, respectively, using high-resolution mass spectrometry, in agreement with our proposed formulas. Second, these structures are based on the mechanism shown in Scheme 2, which follows the same acid-catalyzed aldol condensation mechanism used to explain the previously identified imidazole derivatives in Table 2 and in De Haan et al. (2011) and Aiona et al. (2017a). Third, the relative abundance of these PBCs in capped and dried samples follows logically from their structures. For example, $m / z 235$ and 253 are related by loss of water and their relative abundance shifts in favor of $m / z 235$ in dried samples. $m / z 162$ likely forms through imine substitution 


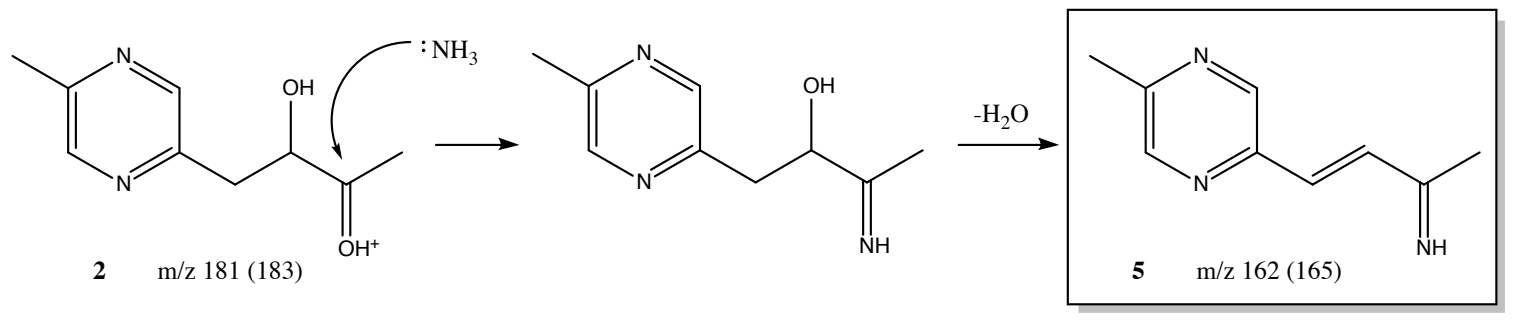

Scheme 3. Proposed formation mechanism of (5) with $m / z, 162$ from (2) (m/z 181) involving imine substitution and dehydration. Masses expected and observed in samples prepared with ${ }^{15} \mathrm{~N}$ are given in parentheses.

and dehydration of $m / z 181$ as shown in Scheme 3. Imine substitution is favored in mildly acidic conditions like those used here and indeed $m / z 162$ is elevated in dried samples and not observed at $\mathrm{pH} 9$. A product with this molecular formula, $\mathrm{C}_{9} \mathrm{H}_{11} \mathrm{~N}_{3}$, was reported in Table 1 of Lin et al. (2015) with an exact mass of 162.10225 , while the structure provided in their Supplement corresponds to a different formula, $\mathrm{C}_{6} \mathrm{H}_{11} \mathrm{O}_{4} \mathrm{~N}$, matching the structure initially reported in Sareen et al. (2010). No structure was provided matching the observed ion $\mathrm{C}_{9} \mathrm{H}_{11} \mathrm{~N}_{3}$, however.

While MG could add to 2,5-DMP directly on the aromatic ring (as in Adams et al., 2008, Scheme 1b), the resulting product mass $m / z 165\left(\mathrm{C}_{9} \mathrm{H}_{13} \mathrm{~N}_{2} \mathrm{O}^{+}\right)$did not rise above the baseline in our spectra. It was observed in Lin et al. (2015); therefore, it likely forms in our reactions as well, just below our detection limit. In Lin et al. (2015) the UV-visible absorption spectrum for $m / z 165$ shows significant absorption beyond $400 \mathrm{~nm}$ (peak 20 in Fig. 3b), which is consistent with the structure in Adams et al. (2008). In fact, this acetylated pyrazine product is known to the flavor industry as having a yellow-brown color. Even though $m / z 165\left(\mathrm{C}_{9} \mathrm{H}_{13} \mathrm{~N}_{2} \mathrm{O}^{+}\right)$itself was not identified in this study, it is highly likely that the observed PBCs contribute to visible light absorption. For example, $m / z 253$ (peak 14 in Lin et al., 2015, Fig. 3b) has significant visible light absorption detected following chromatographic separation. Further, the structural similarity between acetyl pyrazine and the products described here suggests that all of the MG addition products should share some visible light absorption, particularly $m / z 162,235$, and 289 , since those compounds have carbonyl or imine groups conjugated to the pyrazine ring. Perhaps more convincing is the work presented in Yu et al. (2017) showing that pyrazines were strongly and positively correlated to browning products from ascorbic acid and amino acids as well as the results of Divine et al. (2012) connecting browning in Parmesan cheese with total pyrazine production. Therefore, the formation of PBCs from Maillard-type reactions under atmospherically relevant conditions has implications for the radiative forcing potential of aqBrC SOA.

Reaction products of the MG-AS system listed in Table 2 are very typical Maillard reaction products, observed in both cloud water simulations (De Haan et al., 2011; Lin et al., 2015; Sareen et al., 2010; Hawkins et al., 2016) and the chemical characterization of baked bread, cooked meat, aged cheese, and other reactions between carbonylcontaining compounds and amines or amino acids (Koehler and Odell, 1970; Adams et al., 2008; Van Lancker et al., 2010; Divine et al., 2012). It is therefore surprising that pyrazine-based products, which are also well-known to form in Maillard reactions in food, have not been identified in the context of atmospheric reactions. One plausible reason that PBCs were not observed in previous analyses is the strong acidity of the $\mathrm{N}$ heteroatom in pyrazine compared with imidazole, leaving most PBCs unprotonated in electrospray solutions. For example, the $\mathrm{pK}_{\mathrm{a}}$ of pyrazine is 0.6 and 2,5DMP is 1.6, whereas imidazole has a $\mathrm{pK}_{\mathrm{a} 1}$ of 6.9 and a $\mathrm{pK}_{\mathrm{a} 2}$ of 14.4. Unless the electrospray ionization solvent or column effluent (in liquid chromatography-mass spectrometry) was acidified below $\mathrm{pH} 2$, there is no reason to expect significant quantities of pyrazine in its acidic, ionized form. Rather, predominant products observed in positive ion mode would be imidazole derivatives. Atmospheric pressure chemical ionization, however, does not require analytes to exist in their ionic form in the sample solution. Instead, the sample is gently ionized through a proton transfer from a hydronium ion. Another reason for their apparent absence is the role that evaporation plays in forming pyrazine compounds. As detailed below, evaporation seems to drive PBC formation, consistent with findings from the food chemistry literature that high water content can inhibit pyrazine formation (Pletney, 2007). Although solutions were dried in De Haan et al. (2011), they were not dried in Lin et al. (2015) and only rapidly dried in Sareen et al. (2010) during atomization for aerosol chemical ionization mass spectrometry (CIMS) analyses.

If drying and chemical ionization are necessary to observe the PBC in the MG-AS system, they should have been reported in Sareen et al. (2010) in which atomized solutions were analyzed by aerosol CIMS. $m / z$ 109, 181, and 235 were in fact observed in that study, but they were assigned to a water cluster and two MG self-reaction products in part due to their appearance in both $\mathrm{AS}$ and $\mathrm{NaCl}$ samples and to the absence of high-resolution spectra necessary to constrain a molecular formula ( $0.5 \mathrm{amu}$ resolution was used). $\mathrm{m} / z .181$ 
was assigned to either $\mathrm{C}_{6} \mathrm{H}_{13} \mathrm{O}_{6}^{+}$or $\mathrm{C}_{6} \mathrm{H}_{11} \mathrm{O}_{5}^{+} \cdot \mathrm{H}_{2} \mathrm{O}$ and $m / z 235$ was assigned to $\mathrm{C}_{9} \mathrm{H}_{15} \mathrm{O}_{7}^{+}$. However, the mass observed for $m / z 181$ (181.2 amu) is slightly closer to our proposed molecular formula $\mathrm{C}_{9} \mathrm{H}_{13} \mathrm{~N}_{2} \mathrm{O}_{2}^{+}$at $181.21 \mathrm{amu}$ than $\mathrm{C}_{6} \mathrm{H}_{13} \mathrm{O}_{6}^{+}$at $181.16 \mathrm{amu}$. Similarly, the exact mass for our proposed formula for $m / z 235\left(\mathrm{C}_{12} \mathrm{H}_{15} \mathrm{~N}_{2} \mathrm{O}_{3}^{+}\right)$is 235.26, which is closer to the observed value of 235.3 than the exact mass for $\mathrm{C}_{9} \mathrm{H}_{15} \mathrm{O}_{7}^{+}$(235.21). While inconclusive, it is possible that the $\mathrm{PBC}$ structures reported here were observed in Sareen et al. (2010) and if so, their abundance in that study is comparable to the abundance observed here since $m / z 181$ and 235 are both prominently featured in Fig. 7 of Sareen et al. (2010). As for their presence in NaCl-containing samples (in which no ammonium was added), we can only speculate that ammonia is notoriously difficult to avoid in many laboratory studies.

\subsection{Role of $\mathrm{pH}$ in chromophore formation}

To explore the role of $\mathrm{pH}$ in this work, we first compare the absorptivity of the capped samples after 1 week of reaction time. Figure $1 \mathrm{c}$ shows that absorptivity across the spectrum is positively correlated with $\mathrm{pH}$. This can also be seen in Figs. 4 and S12; Fig. S12 is a photograph of sample vials taken $24 \mathrm{~h}$ after adding MG to AS. In our study, absorbance has been normalized by TOC concentration for each sample to provide a bulk solution phase mass absorption coefficient, which accounts for the loss of any organic carbon to the gas phase. The results in Fig. 1c are consistent with Kampf et al. (2012) and Yu et al. (2011) and suggest that over a pH range between 2 and 9, the role of nitrogen as a nucleophile is more important for chromophore formation than acid-catalyzed aldol condensation. The observed changes in absorptivity (rather than absorbance) imply that solution $\mathrm{pH}$ can promote one product (like MG self-reaction products) at the expense of another (N-containing products) or that unreacted MG remains in the solution after 1 week. However, none of the APCI spectra show peaks for unreacted MG $(m / z 73)$ or hydroxyacetone $(m / z 75)$ observed in the control samples and in spectra collected soon after mixing the reactants. This suggests that MG completely reacts with itself or ammonia (or sulfate) in 1 week. Therefore, the higher absorptivity observed at $\mathrm{pH} 9$ suggests that stronger chromophores preferentially form under mildly basic conditions.

Figure 5 shows APCI spectra for the same four capped solutions after 1 week of reaction. The most consistently prominent ions are $m / z 83$ and 125 , both imidazoles and both shown in Scheme 2 of De Haan et al. (2011). m/z 125 makes up more than $60 \%$ of the peak area in $\mathrm{pH} 2$ and $\mathrm{pH} 5$ samples. This ion was observed in Lin et al. (2015) and De Haan et al. (2011) and assigned to 4-methyl-2-acetyl imidazole (MAI), which is the MG analog of imidazole carboxyaldehyde (IC) reported in Galloway et al. (2009), Yu et al. (2011), and Kampf et al. (2012) using glyoxal instead of MG. $m / z 83$ is 4-methyl imidazole (MI) generated by loss of

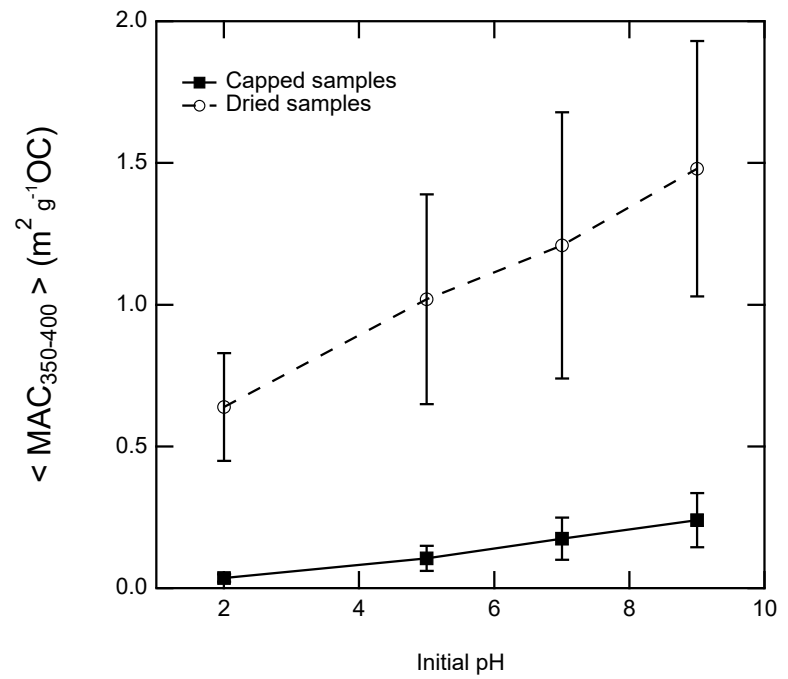

Figure 4. Solution-based mass absorption coefficients (MACs) calculated from $350-400 \mathrm{~nm}$ as a function of initial solution $\mathrm{pH}$ for both capped and dried samples. While both capped and dried samples become more absorptive in basic conditions, the $\mathrm{pH}$ dependence is more severe following evaporation to dryness. All samples in this table were analyzed after 7 days of reaction.

a $\mathrm{C} 2$ group from the precursor to MAI. In the $\mathrm{pH} 7$ samples, the $m / z 125$ contribution drops below $15 \%$ even though it is still the largest signal. At $\mathrm{pH} 9, \mathrm{~m} / z 125$ is still about $15 \%$ of the peak area but the largest signal belongs to $m / z 83$ with $24 \%$ of the peak area. These two major products appear to form in competition with one another, again consistent with Scheme 2 in De Haan et al. (2011). Only one pathway, however, promotes further oligomerization by aldol condensation and that pathway forms $m / z, 125$ and appears to be favored in the more acidic samples. A third major product in the basic samples is $m / z 97$ (dimethylimidazole), which is also shown in Scheme 2 of De Haan et al. (2011); we observe this ion under neutral and basic conditions when $m / z 83$ is prominent, consistent with that mechanism. Given that the pathway leading to further oligomerization by aldol condensation is favored under acidic conditions, it is curious that the basic samples possess higher absorptivity. This observation suggests that the previously reported imidazole oligomers formed by condensation are not primarily responsible for the dark brown color of most basic MG-AS solutions, though they are likely to contribute some light absorption in all samples.

Overall, $\mathrm{pH} 2$ and 5 capped samples do not display a large difference in the product distribution based on visual interpretation despite the fact that the $\mathrm{pH} 5$ sample is clearly more absorptive. Looking closely, the PBC at $m / z 181$ increases from $2.5 \%$ of the signal to $3.7 \%$ and $m / z 162$ increases from $1.1 \%$ to $2.4 \%$ at $\mathrm{pH} 5$, though using relative peak area from APCI data is only semiquantitative. These increases accompany a $10 \%$ drop in the contribution from 


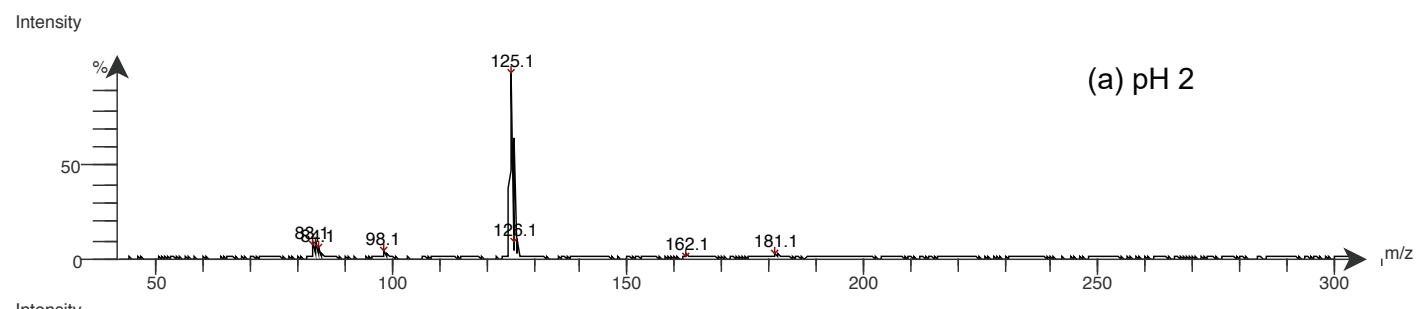

Intensity

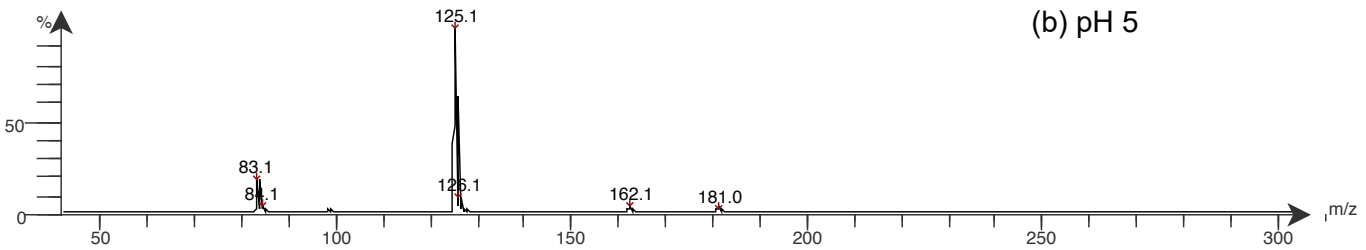
Intensity

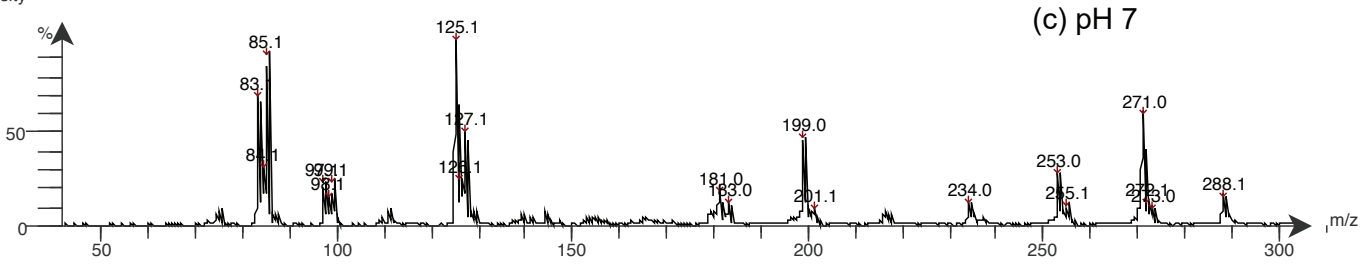

Intensity

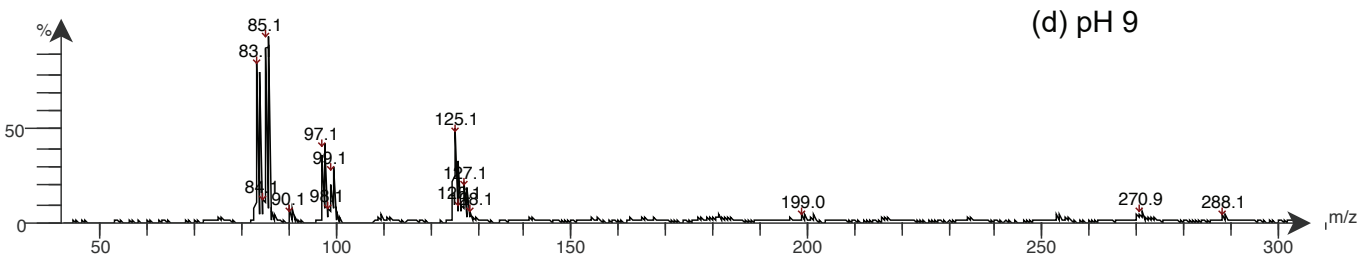

Figure 5. Atmospheric pressure chemical ionization (APCI) mass spectra for all four initial pH conditions in the reaction between $1.0 \mathrm{M}$ methylglyoxal and 1.0 M ammonium sulfate, in capped samples, analyzed after 7 days. Intensity is set to $100 \%$ for the largest signal and does not correspond to concentration in the sample itself.

$m / z$ 125. At $\mathrm{pH} 7$, two MG self-reaction products become visible, $m / z 199$ and 271 , totalling $17.6 \%$ of the signal. Also at $\mathrm{pH} 7$, dimethylimidazole appears. The largest PBC signal at $\mathrm{pH} 7$ is $m / z 253$ at $3.2 \%$ (seen in the ${ }^{15} \mathrm{~N}$ sample at $m / z 255$ ). Interestingly, at $\mathrm{pH} 9$ the product distribution changes dramatically, and the largest signal is $m / z 83$ (MI) with dimethylimidazole $(\mathrm{m} / \mathrm{z}, 97)$ and MAI $(\mathrm{m} / \mathrm{z}, 125)$ close behind. One explanation for the dramatic shift in the product distribution is that the $\mathrm{pK}_{\mathrm{a}}$ of ammonium is 9.24 and at $\mathrm{pH} 9$, nearly $40 \%$ of the ammonium is present as ammonia while at $\mathrm{pH} 7$, the fraction is less than $1 \%$. Neither methylimidazole nor dimethylimidazole are known to have significant visible light absorbance, yet the $\mathrm{pH} 9$ solution has the highest absorptivity. Over $80 \%$ of the peak area in the $\mathrm{pH} 9$ sample can be accounted for without including any known (or likely) visible light-absorbing products. Because the absorptivity metric accounts for OC concentration, we cannot simply attribute the higher absorptivity to a higher concentration of chromophores driven by the faster reaction rate under basic conditions. Rather, this result supports the pre- viously proposed idea that a few highly absorbing species, present at low concentrations, are driving the overall absorption (Nguyen et al., 2012). For example, $m / z 126(1.3 \%$ of signal) is the dehydration product of $m / z 144$ (Table 2) and has a series of four conjugated double bonds. Similarly, $m / z 180$ ( $0.9 \%$ of signal) has six conjugated double bonds. However, these two particular compounds are present at higher relative concentrations in the $\mathrm{pH} 7$ sample than at $\mathrm{pH} 9$, which means that either the $\mathrm{pH} 9$ sample contains additional strong chromophores or that the $\mathrm{pH} 7$ sample contains some non-absorbing products absent at $\mathrm{pH} 9$.

Figure 6 illustrates the comparison among the $\mathrm{pH} 2-9$ capped samples over the high mass region. Intensity is calculated relative to the single largest signal and is therefore not a useful metric for comparing concentrations across the four samples shown. However, it is clear that the $\mathrm{pH} 2$ and 5 solutions have more PBCs $(m / z 181$ and 162) than other high mass products while at $\mathrm{pH} 7$, the MG self-reaction products at $m / z 199$ and 271 are the predominant products. At $\mathrm{pH} 7$ 9 , the contribution of masses greater than $m / z 200$ increases, 
Intensity

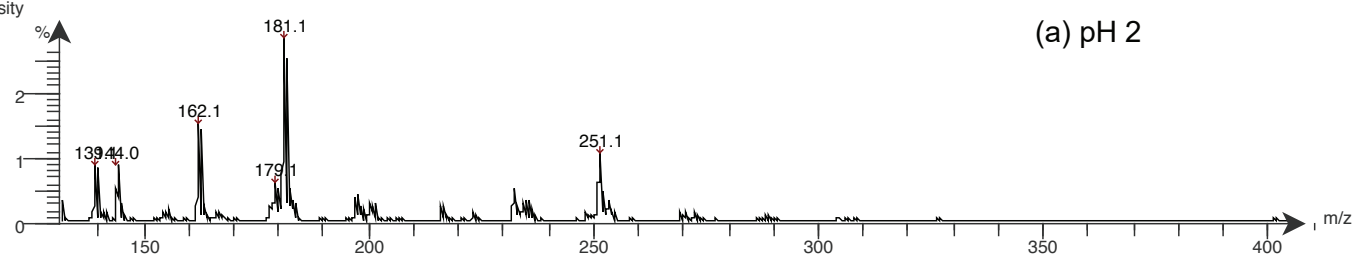
Intensity
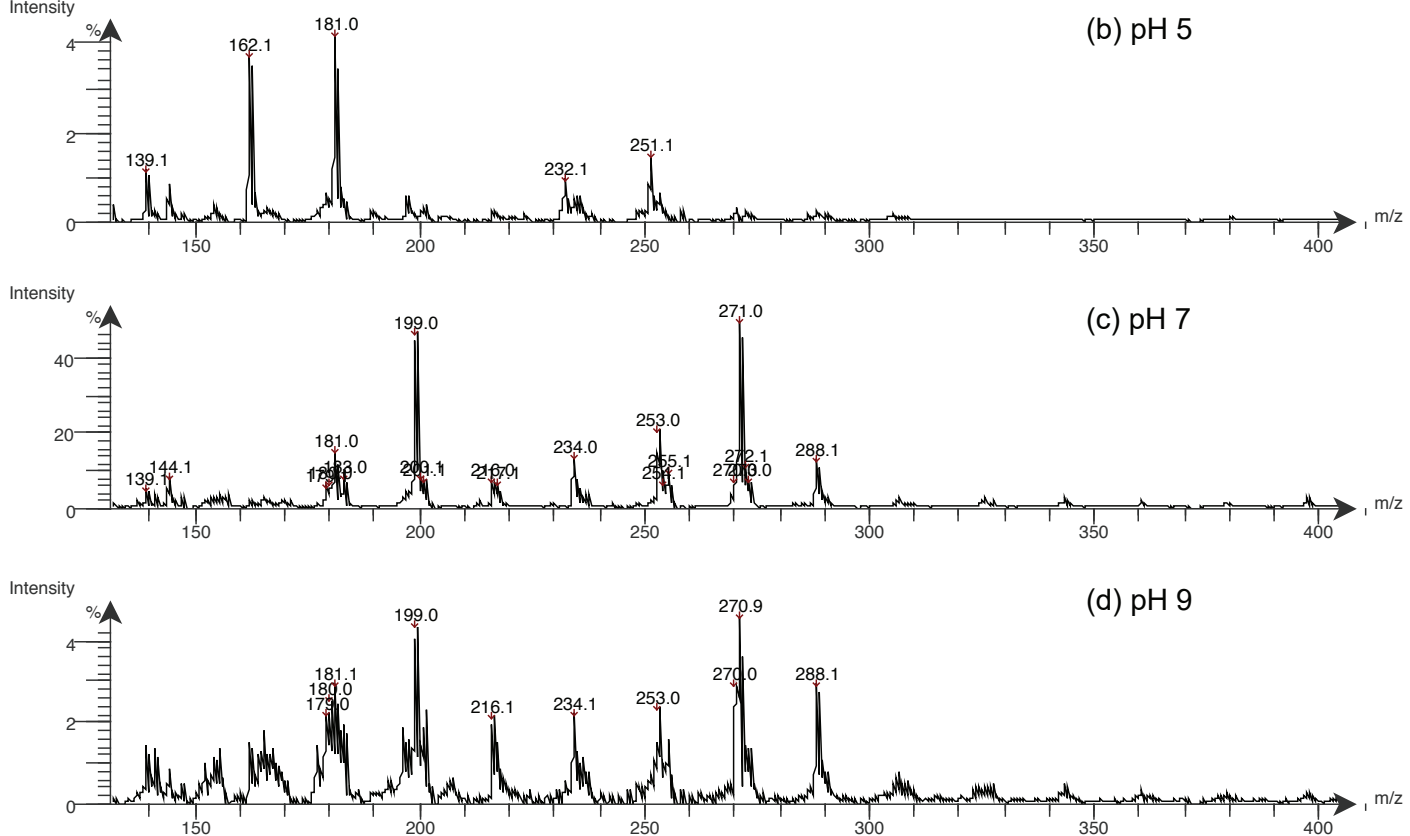

Figure 6. Atmospheric pressure chemical ionization (APCI) mass spectra for $m / z$ greater than 130 for all four initial $\mathrm{pH}$ conditions in capped samples after 7 days. Intensity is set to $100 \%$ for the largest signal and does not correspond to concentration in the sample itself.

in particular $m / z 234$ and 288 (Table 2). $m / z 234$ is the triple dehydration product of $\mathrm{m} / z 288$, a linear imine-containing aldol condensation product. Once dehydrated, this product contains a series of eight conjugated pi systems, giving it the potential to absorb well into the visible region. The percent area attributed to $m / z 234$ and 288 increases from undetectable at $\mathrm{pH} 2$ and 5 to $1 \%-2 \%$ at $\mathrm{pH} 7-9$. Although the $\mathrm{pH} 7$ sample has a larger contribution from $m / z 234$ and 288 , it also has a very large contribution from non-absorbers $m / z 199$ and 271. Together those two products make up a larger fraction of signal than any other product observed in the $\mathrm{pH} 7$ spectrum (17.6\%). Further quantitative characterization is necessary before attributing specific products to the pH-dependent absorptivity observed here, but oligomers with masses beyond $m / z 200$ may be responsible for the observed absorptivity of these solutions.

A more unique $\mathrm{pH}$ dependence was observed for PBCs. The contribution of all observed PBCs to the total signal as a function of $\mathrm{pH}$ and evaporation is shown in Fig. 7. We observed an increase in PBC contribution from $4.4 \%$ to $7.4 \%$ from $\mathrm{pH} 2$ to 7 , with a dramatic drop to $2.2 \%$ at $\mathrm{pH} 9$ (contrasting the proportional relationship between $\mathrm{pH}$ and

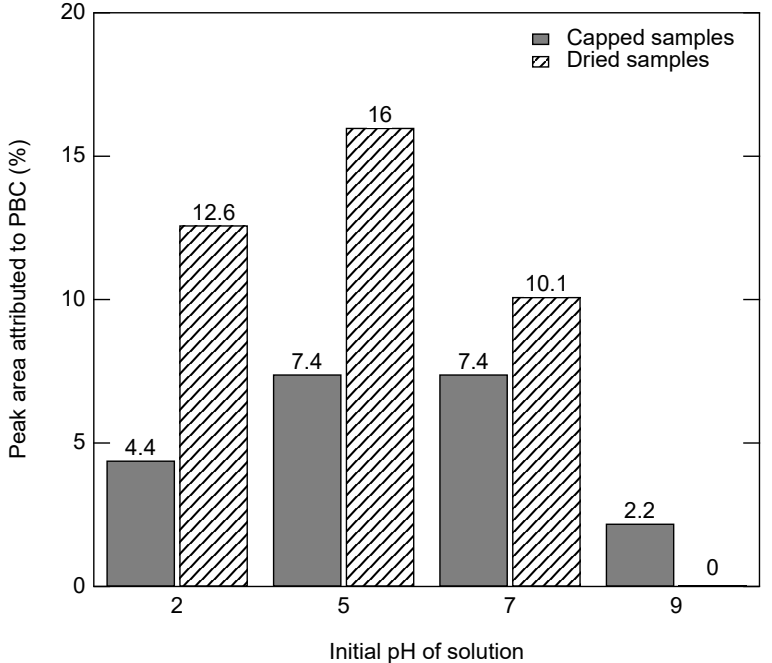

Figure 7. Estimated contribution of PBC to the total ion signal calculated as the sum of the "percent peak areas" for masses $m / z 109$, $162,181,235,253$, and 289. Many of these masses were below the detection limit in one or more sample. 

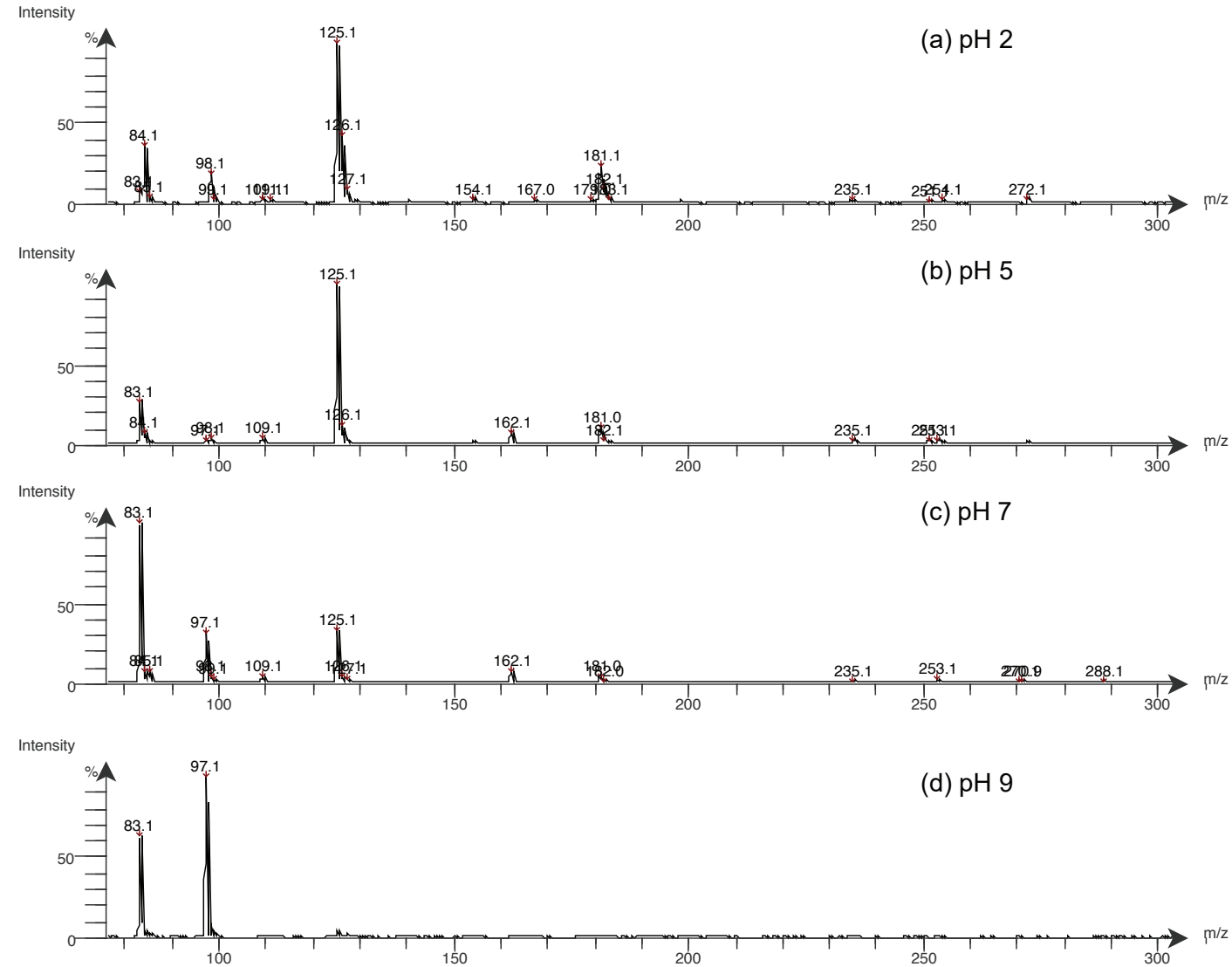

Figure 8. Atmospheric pressure chemical ionization (APCI) mass spectra for all four initial $\mathrm{pH}$ conditions in the reaction between $1.0 \mathrm{M}$ methylglyoxal and 1.0 M ammonium sulfate in dried samples after 7 days. Intensity is set to $100 \%$ for the largest signal and does not correspond to concentration in the sample itself.

absorptivity). Mildly acidic conditions should favor PBCs given the proposed mechanism in Scheme 1 since reductive amination is favored with some acidity, but highly acidic solutions inhibit nucleophilic attack by ammonia on the aldehyde. While absorptivity on the whole increases with $\mathrm{pH}$, the contribution from PBCs to brown carbon absorbance is greatest under acidic conditions. The role of $\mathrm{pH}$ in the dried samples is discussed further in the next section in which the effect of evaporation is considered.

\subsection{Role of evaporation in chromophore formation}

Figure 1c shows that under the range of acidities studied, evaporation increased the absorptivity across the entire UVvisible spectrum and generated a noticeable shoulder around $350 \mathrm{~nm}$ with a tail that extends beyond $550 \mathrm{~nm}$. In the capped samples, the tail extends only to $425 \mathrm{~nm}$. In previous comparisons, absorbance spectra from dried and redissolved material displayed narrower peaks than the slowly aged samples (Nguyen et al., 2012). This difference was attributed to the time allowed for reaction, with the assumption that over short reaction times, the number of different products form- ing may be limited, creating narrow peaks in the absorbance spectra. However, the dried samples in this work reacted for the same length of time as the capped samples, and at the same temperature. This may explain why the peaks in absorbance spectra for our dried samples are as broad as the capped (aqueous aging) samples. As in Nguyen et al. (2012), the brown residual material was stable with respect to hydrolysis for at least several days. The $\mathrm{pH}$ dependence of absorptivity in the dried samples mirrors the capped samples, with the $\mathrm{pH} 9$ dried sample being the most absorptive. Evaporation does not appear to change the relationship between $\mathrm{pH}$ and absorptivity. In fact, in both the aqueous and dried samples, the $\mathrm{pH}$ dependence of absorptivity between 350 and $400 \mathrm{~nm}$ is nearly linear (Fig. 4), though the dried samples show a stronger dependence on $\mathrm{pH}$ than the capped samples. One of the most significant findings of this work is that the $\mathrm{pH} 2$ dried sample was more absorptive than the $\mathrm{pH} 9$ capped sample (by $0.4 \mathrm{~m}^{2} \mathrm{~g}^{-1}$ over the $350-400 \mathrm{~nm}$ range), suggesting that cloud processing may enhance Maillard chemistry despite the role of cloud water acidity in suppressing the nucleophilic behavior of ammonia and amines. That is, evapo- 

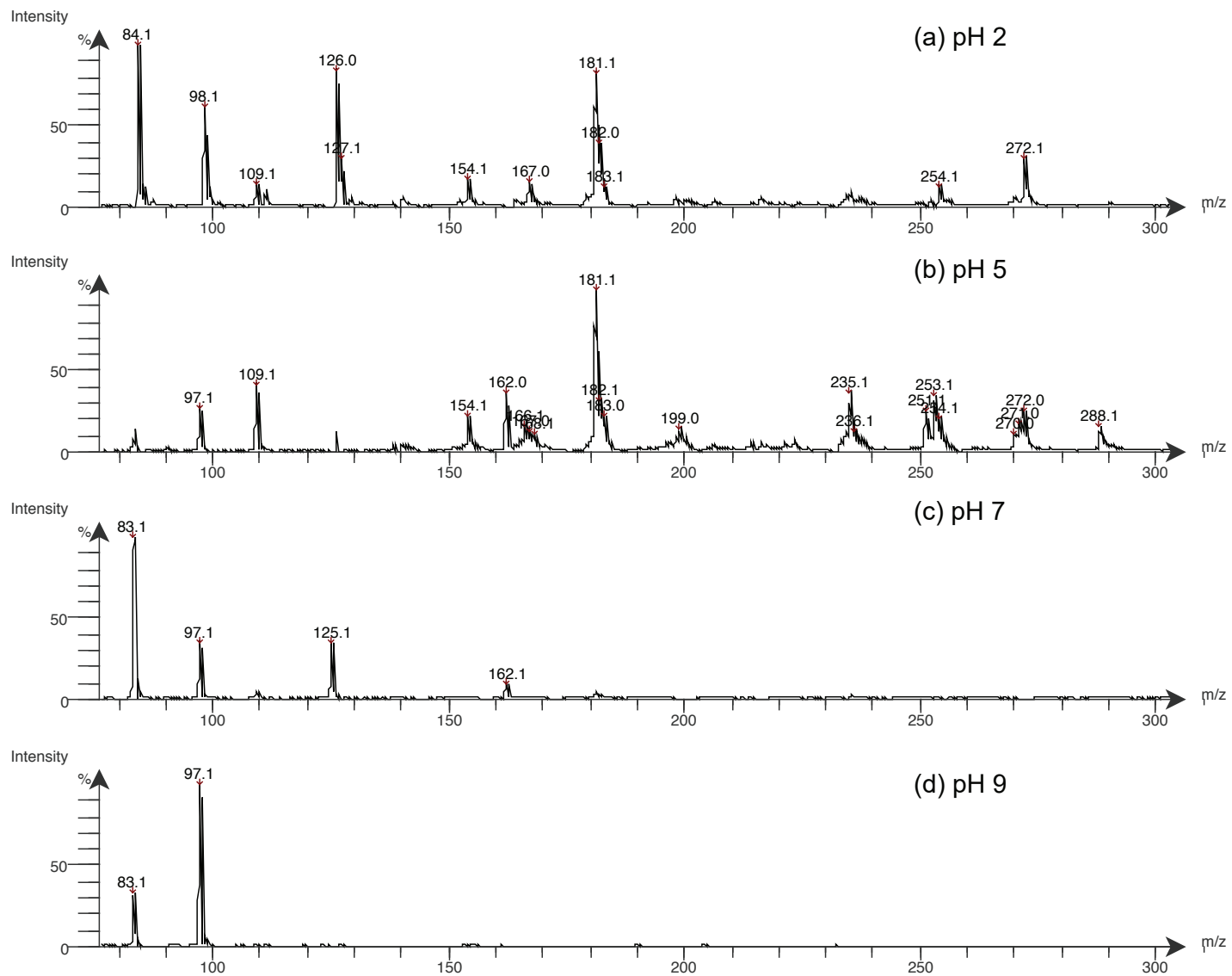

Figure 9. Atmospheric pressure chemical ionization (APCI) mass spectra for all four initial pH conditions in dried samples after subtraction of capped sample spectra for each corresponding sample. Intensity is set to $100 \%$ for the largest signal after subtraction and does not correspond to concentration in the sample itself.

rating acidic cloud droplets allows browning beyond that observed in even the most basic conditions. This effect is also visible in the AAE illustrated in Fig. 1d. A larger difference exists between dried and capped samples, rather than acidic and basic ones.

Given the number of water elimination steps in forming the products described here and in related studies, the observed effect of evaporation is unsurprising. However, it is important to note that in these experiments, evaporation was allowed to occur slowly, over a period of up to 7 days. Cloud processing occurs on much shorter timescales, for which evaporation might not be able to generate the absorptivity observed here. To assess the validity of our approach, we also conducted some preliminary analyses to determine if brown/yellow color and pyrazine products can form over short times as observed with glyoxal and AS in Lee et al. (2013). Absorption spectra from a pH 5 MG and AS reaction are shown in Fig. S13 and APCI spectra are shown in Figs. S14-S16. Figure S13 illustrates that samples dried over the course of $1 \mathrm{~h}$ have significantly lower absorptivity than samples dried slowly over 1 week. However, after
$24 \mathrm{~h}$ the material was noticeably more colored and visibly slightly wet. We observed that the $\mathrm{pH} 5$ dried samples (after $24 \mathrm{~h}$ ) were equally as absorptive as the reaction at $\mathrm{pH} 9$ after 7 days. Future studies are needed to quantify the time dependence of chromophore formation following evaporation to near dryness as this closely mimics atmospheric conditions.

Figures S14-S15 illustrate that PBCs can form on the timescale of $1 \mathrm{~h}$. For example, $m / z 162,181$, and 235 are all visible in Fig. S14b and c, showing mass spectra of the airdried samples. Similar results were obtained for drying under high-purity nitrogen, though the product distribution in Fig. S15b favors imine- and imidazole-based products over the pyrazine products. One possible explanation for this is the role that atmospheric oxygen plays in Scheme 1 to form 2,5-dimethylpyrazine. Figure S16 shows the mass spectrum from a droplet scale experiment, in which a solution containing $50 \mathrm{mM} \mathrm{MG}$ and $50 \mathrm{mM}$ AS was atomized, dried by diffusion, and sampled directly onto the capillary for APCI analysis. Here, imines $(m / z, 144,234$, and 306) and MG selfreaction products (such as $m / z$ 199) are visible. Additional 
studies of this nature are needed to determine if the effects of surface area are important for both the chemical composition and absorptivity of the products.

Figure 8 shows the APCI spectra of the residual material obtained from dried samples for $\mathrm{pH} 2-9$. As with the capped samples, the contribution from $m / z 125$ decreases with $\mathrm{pH}$ while the C2 loss pathway in De Haan et al. (2011) $(m / z 83$ and 97) is increasingly favored with higher $\mathrm{pH}$. PBCs appear only in the acidic and neutral samples, and $m / z 97$ appears only in the neutral and basic samples. Unlike in the capped samples, however, the MG self-reaction products $(\mathrm{m} / z 199$ and 271) are nearly gone. One exception is $m / z 167$, which appears in the baseline of the $\mathrm{pH} 2$ sample. The differences between capped and dry samples are better observed in Fig. 9 in which the capped sample spectrum for each $\mathrm{pH}$ is used as the background signal for the dried sample spectra. In both acidic samples we see a new peak, $m / z 272$, an unknown product with one nitrogen atom. At $\mathrm{pH} 2, m / z 181$ contributes over $10 \%$ of the observed signal compared with $2.5 \%$ in the capped sample. At pH 5, most of the PBCs are prominently visible, including $m / z 109,162,181,235$, and 253 totalling $16 \%$ of signal (Fig. 7). Contribution of PBCs to the total signal in the dried $\mathrm{pH} 5$ sample is noteworthy since this sample is arguably the most similar to ambient-cloudprocessed secondary aerosol material. At $\mathrm{pH} 7$, the PBC contribution drops to $10.1 \%$; although that still places the $\mathrm{pH} 7$ sample well above any of the capped samples, with a maximum PBC contribution of $7.4 \%$. At $\mathrm{pH} 9$, no PBCs were observed in the dried sample. Another interesting trend visible only in the dried samples is the relative contribution of $m / z 162$ and 181 as the predominant PBC species. At $\mathrm{pH} 2$, $\mathrm{m} / z 162$ is not detected while $m / z 181$ is just over $10 \%$ of the total signal, at pH 5 the ratio of $m / z 162: 181$ is 0.8 and at $\mathrm{pH} 7$ the ratio is about 1.6 with $\mathrm{m} / z 162$ making up $3.7 \%$ of signal. Neither was detected at $\mathrm{pH} 9 . \mathrm{m} / z 162$ is the iminesubstituted and dehydrated version of $m / z 181$ (Scheme 3) and the necessary substitution may be favored under the higher ammonia concentration of the neutral solution.

\section{Conclusions}

This study provides compelling evidence for the presence of novel pyrazine-based chromophores in the product mixture resulting from aqueous Maillard-type reactions between MG and AS. The presence of these PBCs has not previously been reported in atmospheric chemistry studies, although their formation from these starting materials and subsequent browning effects have been widely observed in Maillard-type reactions in food chemistry. Both the absorptivity and the relative abundance of the various PBCs showed a clear dependence on sample $\mathrm{pH}$. Absorptivity was greatest under basic conditions and comparable to ambient measurements while PBCs had the most significant contribution to products detected by APCI (up to $16 \%$ ) in samples at or below pH 5 .
The appearance of PBCs in acidic and dried samples indicates that PBCs' contribution to absorbance is likely nonnegligible in cloud, fog, and aerosol water. It is notable that while absorptivity showed a positive linear dependence on sample $\mathrm{pH}$, evaporation was shown to overcome the barrier to aqBrC formation imposed by acidic conditions. Evaporation of even the most acidic sample resulted in an array of products with higher average absorptivity than the most basic unevaporated sample. Future work is needed to quantify the respective contributions of PBCs and other chromophores to absorbance using chromatography coupled to mass spectrometry, to confirm the structural assignments proposed in this work, and to identify PBCs in other related systems as well as in atmospheric samples. Further, these compounds are less likely to be observed by electrospray-based analyses because of their acidity so their formation and loss under atmospheric conditions and in atmospheric samples needs to be quantified in targeted studies.

Data availability. APCI and absorption spectra are publicly available as text files at https://www.hmc.edu/chemistry/ lelia-n-hawkins-publications (last access: 21 August 2018).

\section{The Supplement related to this article is available online at https://doi.org/10.5194/acp-18-12413-2018- supplement.}

Author contributions. HGW generated samples and collected UVvisible absorption spectra. MVA generated samples and collected APCI mass spectra. LNH generated isotopically labeled samples and generated both UV-visible and APCI spectra. LNH wrote the paper.

Competing interests. The authors declare that they have no conflict of interest.

Acknowledgements. The authors would like to acknowledge David Vosburg for his intellectual contribution to the pyrazine formation mechanisms. Lelia Nahid Hawkins was supported by NSF AGS-1555003, Research Corporation Cottrell College Award 22473, and the Barbara Stokes Dewey Foundation. Hannah Greer Welsh was supported by the Kubota Fellows Program of the Harris Family Research Fund in Chemistry.

Edited by: Alexander Laskin

Reviewed by: four anonymous referees 


\section{References}

Adams, A., Polizzi, V., van Boekel, M., and De Kimpe, N.: Formation of pyrazines and a novel pyrrole in Maillard model systems of 1, 3-dihydroxyacetone and 2-oxopropanal, J. Agr. Food Chem., 56, 2147-2153, 2008.

Aiona, P. K., Lee, H. J., Leslie, R., Lin, P., Laskin, A., Laskin, J., and Nizkorodov, S. A.: Photochemistry of Products of the Aqueous Reaction of Methylglyoxal with Ammonium Sulfate, ACS Earth and Space Chemistry, 1, 522-532, 2017a.

Aiona, P. K., Lee, H. J., Lin, P., Heller, F., Laskin, A., Laskin, J., and Nizkorodov, S. A.: A Role for 2-Methyl Pyrrole in the Browning of 4-Oxopentanal and Limonene Secondary Organic Aerosol, Environ. Sci. Technol., 51, 11048-11056, 2017b.

Baduel, C., Voisin, D., and Jaffrezo, J.-L.: Seasonal variations of concentrations and optical properties of water soluble HULIS collected in urban environments, Atmos. Chem. Phys., 10, 40854095, https://doi.org/10.5194/acp-10-4085-2010, 2010.

Bahadur, R., Praveen, P. S., Xu, Y., and Ramanathan, V.: Solar absorption by elemental and brown carbon determined from spectral observations, P. Natl. Acad. Sci. USA, 109, 17366-17371, 2012.

Bones, D. L., Henricksen, D. K., Mang, S. A., Gonsior, M., Bateman, A. P., Nguyen, T. B., Cooper, W. J., and Nizkorodov, S. A.: Appearance of strong absorbers and fluorophores in limonene$\mathrm{O}_{3}$ secondary organic aerosol due to $\mathrm{NH}_{4}^{+}$-mediated chemical aging over long time scales, J. Geophys. Res.-Atmos., 115, D05203, https://doi.org/10.1029/2009JD012864, 2010.

De Haan, D. O., Corrigan, A. L., Smith, K. W., Stroik, D. R., Turley, J. J., Lee, F. E., Tolbert, M. A., Jimenez, J. L., Cordova, K. E., and Ferrell, G. R.: Secondary organic aerosol-forming reactions of glyoxal with amino acids, Environ. Sci. Technol., 43, 28182824, 2009a.

De Haan, D. O., Corrigan, A. L., Tolbert, M. A., Jimenez, J. L., Wood, S. E., and Turley, J. J.: Secondary organic aerosol formation by self-reactions of methylglyoxal and glyoxal in evaporating droplets, Environ. Sci. Technol., 43, 8184-8190, 2009b.

De Haan, D. O., Hawkins, L. N., Kononenko, J. A., Turley, J. J., Corrigan, A. L., Tolbert, M. A., and Jimenez, J. L.: Formation of nitrogen-containing oligomers by methylglyoxal and amines in simulated evaporating cloud droplets, Environ. Sci. Technol., 45, 984-991, 2011.

Divine, R., Sommer, D., Lopez-Hernandez, A., and Rankin, S.: Evidence for methylglyoxal-mediated browning of Parmesan cheese during low temperature storage, J. Dairy Sci., 95, 2347-2354, 2012.

Duarte, R. M., Pio, C. A., and Duarte, A. C.: Synchronous scan and excitation-emission matrix fluorescence spectroscopy of watersoluble organic compounds in atmospheric aerosols, J. Atmos. Chem., 48, 157-171, 2004.

Feng, Y., Ramanathan, V., and Kotamarthi, V. R.: Brown carbon: a significant atmospheric absorber of solar radiation?, Atmos. Chem. Phys., 13, 8607-8621, https://doi.org/10.5194/acp13-8607-2013, 2013.

Fu, T.-M., Jacob, D. J., Wittrock, F., Burrows, J. P., Vrekoussis, M., and Henze, D. K.: Global budgets of atmospheric glyoxal and methylglyoxal, and implications for formation of secondary organic aerosols, J. Geophys. Res.-Atmos., 113, D15303, https://doi.org/10.1029/2007JD009505, 2008.
Galloway, M. M., Chhabra, P. S., Chan, A. W. H., Surratt, J. D., Flagan, R. C., Seinfeld, J. H., and Keutsch, F. N.: Glyoxal uptake on ammonium sulphate seed aerosol: reaction products and reversibility of uptake under dark and irradiated conditions, Atmos. Chem. Phys., 9, 3331-3345, https://doi.org/10.5194/acp-93331-2009, 2009.

Hawkins, L. N., Lemire, A. N., Galloway, M. M., Corrigan, A. L., Turley, J. J., Espelien, B. M., and De Haan, D. O.: Maillard chemistry in clouds and aqueous aerosol as a source of atmospheric humic-like substances, Environ. Sci. Technol., 50, 7443-7452, 2016.

Hecobian, A., Zhang, X., Zheng, M., Frank, N., Edgerton, E. S., and Weber, R. J.: Water-Soluble Organic Aerosol material and the light-absorption characteristics of aqueous extracts measured over the Southeastern United States, Atmos. Chem. Phys., 10, 5965-5977, https://doi.org/10.5194/acp-10-5965-2010, 2010.

Kampf, C. J., Jakob, R., and Hoffmann, T.: Identification and characterization of aging products in the glyoxal/ammonium sulfate system - implications for light-absorbing material in atmospheric aerosols, Atmos. Chem. Phys., 12, 6323-6333, https://doi.org/10.5194/acp-12-6323-2012, 2012.

Kirillova, E. N., Andersson, A., Sheesley, R. J., Kruså, M., Praveen, P., Budhavant, K., Safai, P., Rao, P., and Gustafsson, Ö.: ${ }^{13} \mathrm{C}$ and ${ }^{14} \mathrm{C}$-based study of sources and atmospheric processing of water-soluble organic carbon (WSOC) in South Asian aerosols, J. Geophys. Res.-Atmos., 118, 614-626, 2013.

Kirillova, E. N., Andersson, A., Han, J., Lee, M., and Gustafsson, Ö.: Sources and light absorption of water-soluble organic carbon aerosols in the outflow from northern China, Atmos. Chem. Phys., 14, 1413-1422, https://doi.org/10.5194/acp-141413-2014, 2014.

Koehler, P. E. and Odell, G. V.: Factors affecting the formation of pyrazine compounds in sugar-amine reactions, J. Agr. Food Chem., 18, 895-898, 1970.

Kwak, E. J., Lee, Y. S., Murata, M., and Homma, S.: Effect of pH control on the intermediates and melanoidins of nonenzymatic browning reaction, LWT-Food Sci. Technol., 38, 1-6, 2005.

Laskin, A., Laskin, J., and Nizkorodov, S. A.: Chemistry of Atmospheric Brown Carbon, Chemical Rev., 115, 4335-4382, 2015.

Laskin, J., Laskin, A., Nizkorodov, S. A., Roach, P., Eckert, P., Gilles, M. K., Wang, B., Lee, H. J., and Hu, Q.: Molecular Selectivity of Brown Carbon Chromophores, Environ. Sci. Technol., 48, 12047-12055, 2014.

Lee, A. K. Y., Zhao, R., Li, R., Liggio, J., Li, S.-M., and Abbatt, J. P. D.: Formation of Light Absorbing Organo-Nitrogen Species from Evaporation of Droplets Containing Glyoxal and Ammonium Sulfate, Environ. Sci. Technol., 47, 12819-12826, https://doi.org/10.1021/es402687w, 2013.

Lin, P., Laskin, J., Nizkorodov, S. A., and Laskin, A.: Revealing brown carbon chromophores produced in reactions of methylglyoxal with ammonium sulfate, Environ. Sci. Technol., 49, 1425714266, 2015.

Nguyen, T. B., Lee, P. B., Updyke, K. M., Bones, D. L., Laskin, J., Laskin, A., and Nizkorodov, S. A.: Formation of nitrogen-and sulfur-containing light-absorbing compounds accelerated by evaporation of water from secondary organic aerosols, J. Geophys. Res.-Atmos., 117, D01207, https://doi.org/10.1029/2011JD016944, 2012. 
Noziere, B., Dziedzic, P., and Córdova, A.: Products and kinetics of the liquid-phase reaction of glyoxal catalyzed by ammonium ions $\left(\mathrm{NH}_{4}^{+}\right)$, The J. Phys. Chem. A, 113, 231-237, 2009.

Pletney, V. N.: Focus on food engineering research and developments, Nova Publishers, New York, 2007.

Powelson, M. H., Espelien, B. M., Hawkins, L. N., Galloway, M. M., and De Haan, D. O.: Brown carbon formation by aqueous-phase carbonyl compound reactions with amines and ammonium sulfate, Environ. Sci. Technol., 48, 985-993, 2013.

Rizz, G. P.: Mechanistic study of alkylpyrazine formation in model systems, Journal of Agricultural and Food Chemistry, 20, 10811085, 1972.

Sareen, N., Schwier, A. N., Shapiro, E. L., Mitroo, D., and McNeill, V. F.: Secondary organic material formed by methylglyoxal in aqueous aerosol mimics, Atmos. Chem. Phys., 10, 997-1016, https://doi.org/10.5194/acp-10-997-2010, 2010.

Srinivas, B. and Sarin, M.: Light absorbing organic aerosols (brown carbon) over the tropical Indian Ocean: impact of biomass burning emissions, Environ. Res. Lett., 8, 044042, https://doi.org/10.1088/1748-9326/8/4/044042, 2013.

Van Lancker, F., Adams, A., and De Kimpe, N.: Formation of pyrazines in Maillard model systems of lysine-containing dipeptides, J. Agr. Food Chem., 58, 2470-2478, 2010.

Wang, X., Heald, C. L., Ridley, D. A., Schwarz, J. P., Spackman, J. R., Perring, A. E., Coe, H., Liu, D., and Clarke, A. D.: Exploiting simultaneous observational constraints on mass and absorption to estimate the global direct radiative forcing of black carbon and brown carbon, Atmos. Chem. Phys., 14, 10989-11010, https://doi.org/10.5194/acp-14-10989-2014, 2014.
Yu, A.-N., Zhou, Y.-Y., and Yang, Y.-N.: Kinetics of browning and correlations between browning degree and pyrazine compounds in 1-ascorbic acid/acidic amino acid model systems, Food Chem., 221, 1678-1684, 2017.

Yu, G., Bayer, A. R., Galloway, M. M., Korshavn, K. J., Fry, C. G., and Keutsch, F. N.: Glyoxal in aqueous ammonium sulfate solutions: products, kinetics and hydration effects, Environ. Sci. Technol., 45, 6336-6342, 2011.

Zhang, X., Lin, Y.-H., Surratt, J. D., Zotter, P., Prévôt, A. S., and Weber, R. J.: Light-absorbing soluble organic aerosol in Los Angeles and Atlanta: A contrast in secondary organic aerosol, Geophys. Res. Lett., 38, L21810, https://doi.org/10.1029/2011GL049385, 2011.

Zhang, X., Lin, Y.-H., Surratt, J. D., and Weber, R. J.: Sources, composition and absorption Ångstrom exponent of light-absorbing organic components in aerosol extracts from the Los Angeles Basin, Environ. Sci. Technol., 47, 3685-3693, 2013.

Zhou, S., Rivera-Rios, J. C., Keutsch, F. N., and Abbatt, J. P. D.: Identification of organic hydroperoxides and peroxy acids using atmospheric pressure chemical ionizationtandem mass spectrometry (APCI-MS/MS): application to secondary organic aerosol, Atmos. Meas. Tech., 11, 3081-3089, https://doi.org/10.5194/amt-11-3081-2018, 2018. 